Article

\title{
The Impact of Equilibrium Gas Pressure and Coal Particle Size on Gas Dynamic Diffusion in Coal
}

\author{
Chengwu Li ${ }^{D}$, Yao Nie *, Jianwei Tian, Yuechao Zhao and Xiaoqian Zhang \\ School of Emergency Management and Safety Engineering, China University of Mining and \\ Technology (Beijing), Beijing 100083, China \\ * Correspondence: nyneil@163.com
}

Received: 24 June 2019; Accepted: 26 August 2019; Published: 28 August 2019

check for updates

\begin{abstract}
The diffusion coefficient of gases in coal varies with time. This study aims to develop an unsteady dynamic diffusion (UDD) model based on the decay of diffusion coefficient with time and the change of integral. This study conducted a series of gas desorption and diffusion experiments with three different combinations of particle sizes and gas pressures and compared the diffusion coefficients of the three models. The UDD model exhibited good fitting results, and both the UDD and bidisperse models fitted the experimental data better than the unipore model. In addition, the dynamic diffusion coefficient $\left(D_{D e}\right)$ decreased rapidly in the initial stage but gradually decreased to a stable level in the later stage. All the effective diffusion coefficients of the three models negatively correlated with the particle size. In the unipore model, the diffusion coefficient of coal samples with three particle sizes increased with gas pressure. In the bidisperse and UDD models, the diffusion coefficients $\left(D_{a e}, D_{i e}\right.$, and $\left.D_{D e}\right)$ of $0.25-0.5 \mathrm{~mm}$ and $0.5-1.0 \mathrm{~mm}$ coal samples increased with gas pressure. However, $D_{D e}$ and $D_{a e}$ of $1.0-1.25 \mathrm{~mm}$ coal samples increased first and then decreased. Furthermore, $D_{i e}$ decreased first and then increased, with no sign of significant pressure dependence. Finally, the correlation and significance between the constant and diffusion coefficient in the UDD model was investigated.
\end{abstract}

Keywords: gas diffusion; unsteady dynamic diffusion model (UDD model); gas pressure; particle size; coal matrix

\section{Introduction}

Gas flow in the coal matrix is usually divided into two stages during gas drainage and Coalbed methane (CBM) recovery in underground coal mines [1], as shown in Figure 1. First, owing to the concentration gradient, gas diffuses from the surface of the coal matrix to the fracture/cleat system, and Fick's law could be used to construct the diffusion model. Second, gas in the fracture system seeps into the underground boreholes or surface wells because of the pressure gradient, which could be described using Darcy's law. During both processes, the gas diffusion coefficient and gas permeability are the key parameters affecting gas flow in coal. Reportedly, the diffusion coefficient of gases could be affected by temperature, moisture, particle size, pressure, and so on [2-5]. During CBM development, coal particles around boreholes break up, and gas pressure is in a dynamic state. Thus, comprehending the impact of particle size and pressure on gas diffusion in coal is imperative. Previously, the impact of particle size on the diffusion coefficient has been investigated. Through experiments and a dynamic diffusion model, Guo et al. demonstrated a positive correlation between the particle size and the diffusion coefficient [6]. However, some studies reported a negative correlation between the particle size and the diffusion coefficient [7]. Regarding the pressure dependence of gas diffusion, Clarkson and Bustin conducted experiments and calculations under 0-5 MPa pressure, which showed that the diffusion coefficient increased monotonously with 
pressure [8]. However, Pone et al. found that the diffusion coefficient decreased with a gas pressure range of 0-3.1 $\mathrm{MPa}$ [9]. Furthermore, other studies revealed no significant correlation between the gas pressure and the diffusion coefficient [10]. Hence, the pressure dependence of gas diffusion remains debatable. Table 1 presents the results of previous studies on pressure dependence of the diffusion coefficient.

Table 1. Summary of previous studies on pressure dependence of diffusion coefficients of gases in coal.

\begin{tabular}{ccccc}
\hline Study & Model & Fluid & $\begin{array}{c}\text { Effect of Increasing Pressure } \\
\text { on Diffusion Coefficients }\end{array}$ & Experiment Conditions \\
\hline Clarkson and Bustin (1999) [8] & $\begin{array}{c}\text { Unipore, } \\
\text { bidisperse }\end{array}$ & $\mathrm{CO}_{2}, \mathrm{CH}_{4}$ & Increase & $0 \begin{array}{c}0 \\
{ }^{\circ} \mathrm{C}, 0-127 \mathrm{KPa} \& \\
0-5 \mathrm{MPa}\end{array}$ \\
\hline Cui et al. (2004) [11] & $\begin{array}{c}\text { Modified } \\
\text { bidisperse }\end{array}$ & $\mathrm{CO}_{2}, \mathrm{CH}_{4}$ & Decrease & $30{ }^{\circ} \mathrm{C}, 0-7 \mathrm{MPa}$ \\
\hline Siemons et al. (2007) [5] & Two exponentials & $\mathrm{CO}_{2}$ & Slow term decreases & $0-6 \mathrm{MPa}, 45^{\circ} \mathrm{C}$ \\
\hline Pone et al. (2009) [9] & $\begin{array}{c}\text { Unipore-like } \\
\text { model }\end{array}$ & $\mathrm{CH}_{4}$ & Decrease & $20^{\circ} \mathrm{C}, 3.1 \mathrm{MPa}$ \\
\hline Pan et al. (2010) [12] & Bidisperse & $\mathrm{CH}_{4}, \mathrm{CO}_{2}$ & $\mathrm{CH}_{4}$ increase. $\mathrm{CO}_{2}$ no change & $26^{\circ} \mathrm{C}, 0-4 \mathrm{MPa}$ \\
\hline Švábová et al. (2012) [3] & $\begin{array}{c}\text { LDF single } \\
\text { parameter }\end{array}$ & $\mathrm{CO}_{2}$ & Decrease & $45 \& 55^{\circ} \mathrm{C}, 0.1-0.8 \mathrm{MPa}$ \\
\hline Sun (2018) [10] & Unipore model & $\mathrm{CH}_{4}, \mathrm{CO}_{2}$ & No obvious regularity & $0-5.2 \mathrm{MPa}$ \\
\hline
\end{tabular}

Usually, the diffusion coefficients of gases are evaluated by fitting the diffusion model of gases in porous media rather than by directly measuring them. In spherical coordinates, studies have presented different diffusion models to elucidate the diffusion behavior of gases in coal, based on Fick's diffusion law. Often, the unipore [13] and bidisperse [14] models are used to fit the diffusion coefficients of gas adsorption/desorption. Compared with the unipore model, the bidisperse model considers the dual diffusion mode of pores in coal, including micropores and macropores. Both the unipore and bidisperse models have been extensively used for the diffusion of gases in porous media, with the bidisperse model exhibiting marginally better fitting performance. Notably, both models assume that the diffusion coefficient $D$ is constant. However, recent studies have demonstrated that the diffusion coefficient correlates negatively with time.

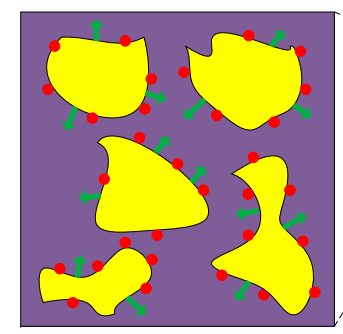

Desorption and diffusion

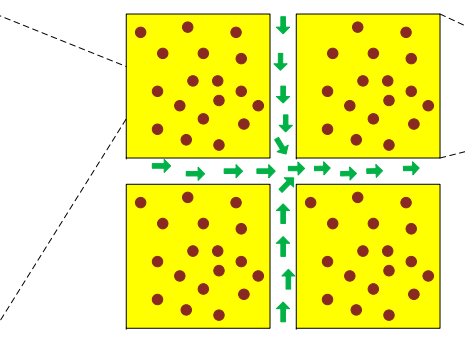

Methane seepage

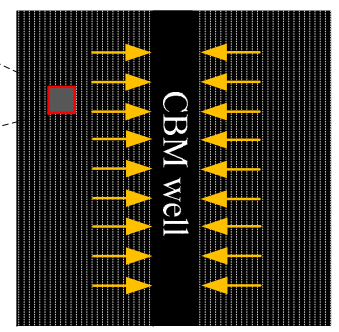

Methane flow to CBM well

Figure 1. Methane migration in coal.

This study summarizes the integral characteristics of diffusion coefficients of different pressures, ranks, and particle sizes of coal in the relevant literature and, accordingly, develops a new unsteady dynamic diffusion (UDD) model to describe the characteristics of gas diffusion in coal. Using the unipore, bidisperse, and UDD models, this study also compares the impact of the particle size and gas pressure on diffusion in coal. Finally, this study discusses the function and significance of coefficients in the UDD model. 


\section{Diffusion Models}

\subsection{Unipore Model}

The diffusion of gases in coal is often described using the unipore model. The assumptions of the unipore model are as follows: (1) The gas concentration on the surface of the particle coal (outside the coal body) is constant; (2) the temperature is constant; (3) the diffusion coefficient is constant; (4) the geometry of the coal body is a standard sphere; and (5) the uniform pore structure exists. Based on Fick's law:

$$
J=-D \frac{\partial C}{\partial x}
$$

where $J$ is the diffusive flux $\left[\mathrm{kg} /\left(\mathrm{m}^{2} \cdot \mathrm{s}\right)\right] ; C$ is the concentration of the diffusion medium $\left(\mathrm{kg} / \mathrm{m}^{3}\right) ; D$ is the diffusion coefficient of fluid $\left(\mathrm{m}^{2} / \mathrm{s}\right)$; and $x$ is the diffusion distance $(\mathrm{m})$.

Pramod argued that the gas flow and diffusion in granular coal could be decreased to a spherical model [15], as shown in Figure 2. Based on the assumptions of homogeneous spherical particles and isothermal conditions, the analytical solution to the unipore gas diffusion coefficients of spherical coal particles is as follows [13]:

$$
\frac{Q_{t}}{Q_{\infty}}=1-\frac{6}{\pi^{2}} \sum_{n=1}^{\infty} \frac{1}{n^{2}} \mathrm{e}^{-\frac{D n^{2} \pi^{2} t}{r^{2}}}
$$

where $Q_{t}$ is the total volume of gas desorbed at time $t(\mathrm{~mL}) ; Q_{\infty}$ is the total desorbed volume after infinite time (mL); $Q_{t} / Q_{\infty}$ is the gas desorption ratio in coal; $r$ is the radius of the spherical coal particle $(\mathrm{mm}) ; n$ is the series; and $D_{\mathrm{e}}\left(\mathrm{s}^{-1}\right)$ is the effective diffusion coefficient $\left(D_{e}=D / r^{2}\right)$.

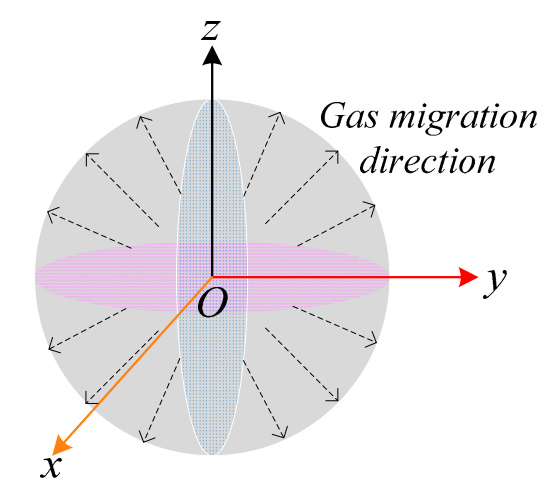

Figure 2. Sketch of gas diffusion in coal.

\subsection{Bidisperse Model}

Considering the dual-aperture distribution in the coal matrix, Ruckenstein et al. introduced the bidisperse model, which explains the fast diffusion stage of macropores and the slow diffusion stage of micropores [12]. The effective diffusion coefficient of coal is evaluated using both the micro-diffusion coefficient and the macro-diffusion coefficient. The macro-diffusion stage can be expressed as follows [16]:

$$
\frac{Q_{a t}}{Q_{a \infty}}=1-\frac{6}{\pi^{2}} \sum_{n=1}^{\infty} \frac{1}{n^{2}} \mathrm{e}^{-\frac{D_{a e n}{ }^{2} \pi^{2} t}{r_{a}^{2}}}
$$

where $Q_{a t}$ is the total volume of gas desorbed in macropores at time $t(\mathrm{~mL}) ; Q_{a \infty}$ is the total desorbed volume after infinite time in the macropores $(\mathrm{mL}) ; D_{a}$ is the diffusion coefficient of macropores; $D_{a e}\left(\mathrm{~s}^{-1}\right)$ is the effective diffusion coefficient of macropores $\left(D_{a e}=D_{a} / r_{a}^{2}\right)$; and $r_{a}$ is the radius (mm).

The micro diffusion stage can be presented as follows:

$$
\frac{Q_{i t}}{Q_{i \infty}}=1-\frac{6}{\pi^{2}} \sum_{n=1}^{\infty} \frac{1}{n^{2}} \mathrm{e}^{-\frac{D_{i e^{n} n^{2} \pi^{2} t}}{r_{i}^{2}{ }^{2}}}
$$


where $Q_{i t}$ is the total volume of gas desorbed in micropores at time $t(\mathrm{~mL}) ; Q_{i \infty}$ is the total desorbed volume after infinite time in the micropores $(\mathrm{mL}) ; D_{i}$ is the diffusion coefficient of micropores; $D_{i e}\left(\mathrm{~s}^{-1}\right)$ is the effective diffusion coefficient of micropores $\left(D_{i e}=D_{i} / r_{i}^{2}\right)$; and $r_{i}$ is the radius (mm).

Combining Equations (3) and (4), the bidisperse model can be expressed as follows [16]:

$$
\frac{Q_{t}}{Q_{\infty}}=\lambda \frac{Q_{a t}}{Q_{a \infty}}+(1-\lambda) \frac{Q_{i t}}{Q_{i \infty}}
$$

where $\lambda$ and $1-\lambda$ provide the ratio information of the macropore/micropore adsorption/desorption to the total adsorption/desorption.

\subsection{UDD Model}

\subsubsection{UDD Model in Coal}

Reportedly, the gas diffusion coefficient in porous media closely correlates with porosity [17]. Usually, macropores on the coal surface have good connectivity and a large throat. On the coal surface, the gas is most likely to diffuse through a large and well-connected pore (the first type of pore), then through the well-connected pore (the second type of pore), and finally through the poorly connected pore (the third type of pore) [18]. In the initial stage, the gas diffusion resistance is small. First, the gas diffuses from the macropores on the coal surface, and the diffused gas occupies the main diffusion path and prevents the gas from diffusing from another pore. Second, the concentration of the main diffusion path declines with the reduction of the gas volume in macropores, thereby increasing the concentration gradient of the second type of pore and the main diffusion path. Thus, the gas begins diffusing from the second type of pore to the main diffusion path, and, finally, the gas enters the main diffusion path from the poorly connected pore. Compared with the first type of pore, the second and third types of pores have weaker connectivity and smaller throat. Thus, the diffusion coefficient decreases with the increase of gas diffusion resistance as the diffusion proceeds.

This study fitted eight groups of gas desorption experimental data from different studies $[19,20]$. The findings revealed that although the gas diffusion coefficients were evaluated using different models or experimental conditions, the integral of the diffusion coefficient $D$ can be calculated using the same relationship (Figure 3). The equation is expressed as follows:

$$
\frac{\xi t^{k}}{1+\beta t^{k}}=\int D d t
$$

where $\xi, \beta$, and $k$ are the constants related to the diffusion coefficients in the UDD model; $\xi$ denotes the initial diffusion coefficient; $\beta$ and $k$ are the constants that regulate the gas diffusion coefficient. Section 5.4 discusses the detail meaning of constants.

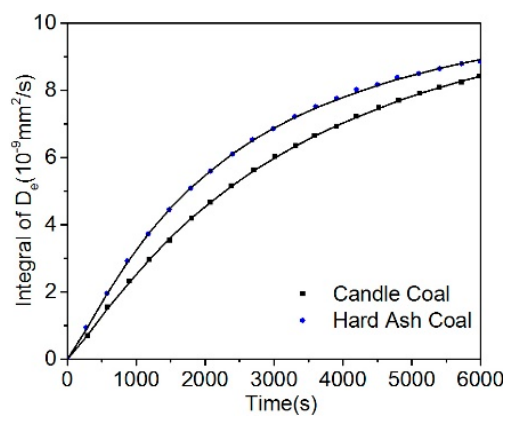

(a)

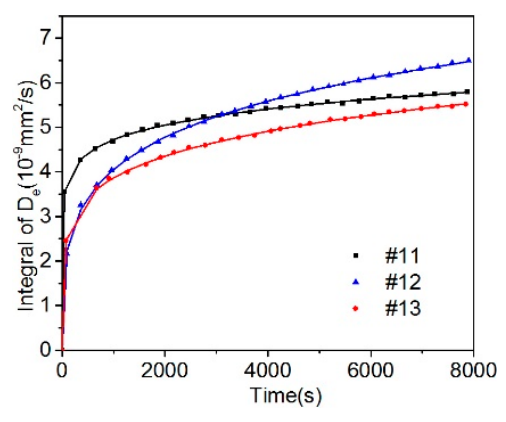

(b)

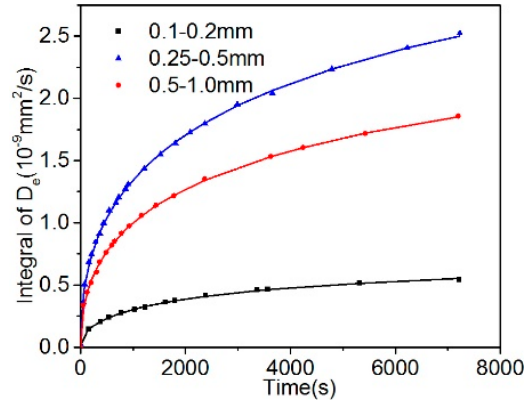

(c)

Figure 3. Integral of the D under different experimental conditions. (a) Coals of different ranks; (b) Different equilibrium pressures; (c) Different particle sizes. 


\subsubsection{Diffusion Model and Initial and Boundary Conditions}

According to Fick's law, gas diffusion is driven by the concentration gradient. In spherical coordinates, it can be expressed as follows:

$$
\frac{\partial C}{\partial t}=D\left(\frac{\partial^{2} C}{\partial r^{2}}+\frac{2}{r} \frac{\partial C}{\partial r}\right)
$$

where $C$ is the desorption concentration $\left(\mathrm{g} / \mathrm{mm}^{3}\right)$ and $r$ is the radius $(\mathrm{mm})$.

Besides the spherical and isothermal assumptions, it is assumed that (1) pores are evenly distributed in the coal matrix, and macropores and micropore sizes are different; (2) gas is evenly distributed in the pores of coal after the gas adsorption equilibrium; (3) the diffusion coefficient $D$ is a function of time $t$, expressed by Equation (6); (4) the paths with a different degree of pore connectivity are isotropic; and (5) the gas concentration on the surface of the particle coal (outside the coal body) is constant. Then, the initial conditions can be expressed as follows:

$$
\left\{\begin{array}{l}
\partial C / \partial t=0(r=0, t>0) \\
C=C_{0}\left(t=0,0 \leq r<r_{0}\right) \\
C=C_{e}(r=R, t>0)
\end{array}\right.
$$

where $C_{0}$ is the initial concentration $\left(\mathrm{g} / \mathrm{mm}^{3}\right)$ and $C_{e}$ is the constant concentration of gas contacting the surface of the sphere $\left(\mathrm{g} / \mathrm{mm}^{3}\right)$.

\subsubsection{Model Solution}

Taking $\Phi=C r$ into Equations (7) and (8), then:

$$
\left\{\begin{array}{l}
\frac{\partial \phi}{\partial t}=D \frac{\partial^{2} \phi}{\partial r^{2}} \\
\phi=r C_{0}(0 \leq r<R, t=0) \\
\phi=R C_{1}(r=R, t>0) \\
\phi=0(r=0, t>0)
\end{array}\right.
$$

Equation (9) is a partial differential equation. The separation of variables was used to solve it. Of note, $\phi$ can be regarded as a function of $r$ and $t$ :

$$
\phi(r, t)=v(r, t)+\omega(r)
$$

Now, substitute Equation (9) into Equation (10), then:

$$
\left\{\begin{array}{l}
\frac{d^{2} \omega}{d r^{2}}=0 \\
\omega(0)=0 \\
\omega(R)=R C_{1}
\end{array}\right.
$$

and

$$
\left\{\begin{array}{l}
\frac{\partial v}{\partial t}=D \frac{\partial^{2} v}{\partial r^{2}} \\
v(0, t)=v(R, t)=0 \\
v(r, 0)=r C_{0}-\omega(r)
\end{array}\right.
$$

The solution to Equation (11) is as follows:

$$
\omega(r)=r C_{e}
$$

Combining Equations (12) and (13), the following is obtained: 


$$
\left\{\begin{array}{l}
\frac{\partial v}{\partial t}=D \frac{\partial^{2} v}{\partial r^{2}} \\
v(0, t)=v(R, t)=0 \\
v(r, 0)=r C_{0}-r C_{1}
\end{array}\right.
$$

The equation $v(r, t)$ can be transformed as follows:

$$
v(r, t)=\gamma(r) T(t)
$$

Combining the first equation of Equations (14) and (15), the following is obtained:

$$
\gamma(r) T^{\prime}(t)=D \gamma^{\prime \prime}(r) T(t)
$$

If

$$
\frac{T^{\prime}(t)}{D T(t)}=\frac{\gamma^{\prime \prime}(r)}{\gamma(r)}=-\lambda
$$

Equation (16) can be transformed as follows:

$$
\left\{\begin{array}{l}
\left\{T^{\prime}(t)+\lambda D T(t)=0\right. \\
\gamma^{\prime \prime}(r)+\lambda \gamma(r)=0
\end{array}\right.
$$

Based on the second equation of Equation (14):

$$
\begin{aligned}
& \gamma(0)=0, \quad \gamma(R)=0, \\
& \left\{\begin{array}{l}
\gamma^{\prime \prime}(r)+\lambda \gamma(r)=0 \\
\gamma(0)=0 \\
\gamma(R)=0
\end{array}\right.
\end{aligned}
$$

The general solution to Equation (20) is as follows:

$$
\left\{\begin{array}{l}
\lambda_{n}=\left(\frac{n \pi}{R}\right)^{2} \\
\gamma_{n}=\sin \frac{n \pi}{R} r
\end{array}\right.
$$

The solution to the second equation in Equation (18) corresponding to $\lambda_{n}$ is as follows:

$$
T(t)=C_{n} \exp \left(-\int \lambda_{n} D d t\right)
$$

where $C_{n}$ is a constant value. Combining Equations (6) and (22), the following can be obtained:

$$
v_{n}(r, t)=\gamma_{n}(r) T_{n}(t)=C_{n} \exp \left(-\lambda_{n} \frac{\xi t^{k}}{1+\beta t^{k}}\right) \sin \left(\frac{n \pi}{R} r\right)
$$

According to the superposition principle,

$$
\begin{gathered}
v(r, t)=\sum_{n=1}^{\infty} C_{n} \exp \left(-\lambda_{n} \frac{\xi t^{k}}{1+\beta t^{k}}\right) \sin \left(\frac{n \pi}{R} r\right) \\
\text { Because } \frac{\xi t^{k}}{1+\beta t^{k}}=0(\text { when } t=0)
\end{gathered}
$$

The following equation can be obtained:

$$
v(r, 0)=r C_{0}-r C_{e}=\sum_{n=1}^{\infty} C_{n} \sin \left(\frac{n \pi}{R} r\right)
$$


where $C_{n}$ is the coefficient of the Fourier sine series expansion of function $\varphi(r)=r C_{0}-r C_{1}$, then:

$$
C_{n}=(-1)^{n} \frac{2 R\left(C_{e}-C_{0}\right)}{n \pi}
$$

The algebraic solution to Equation (12) can be obtained by combining Equations (27) and (23):

$$
v(r, t)=\sum_{n=1}^{\infty}(-1)^{n} \frac{2 R\left(C_{e}-C_{0}\right)}{n \pi} \exp \left(-\left(\frac{n \pi}{R}\right)^{2} \frac{\xi t^{k}}{1+\beta t^{k}}\right) \times \sin \left(\frac{n \pi}{R} r\right)
$$

Thus,

$$
\begin{gathered}
\phi(r, t)=v(r, t)+\omega(r)=\sum_{n=1}^{\infty}(-1)^{n} \frac{2 R\left(C_{e}-C_{0}\right)}{n r} \exp \left(-\left(\frac{n \pi}{R}\right)^{2} \frac{\xi t^{k}}{1+\beta t^{k}}\right) \times \sin \left(\frac{n \pi}{R} r\right)+r C_{e} \\
C(r, t)=\frac{\phi(r, t)}{r}=\frac{2 R\left(C_{e}-C_{0}\right)}{\pi r} \sum_{n=1}^{\infty} \frac{(-1)^{n}}{n} \exp \left(-\left(\frac{n \pi}{R}\right)^{2} \frac{\xi t^{k}}{1+\beta t^{k}}\right) \times \sin \left(\frac{n \pi}{R} r\right)+C_{e}
\end{gathered}
$$

The final desorbed gas volume can be evaluated as follows:

$$
Q_{t}=\iiint_{v}\left(C_{0}-C(r, t)\right) d V=\frac{4 \pi R^{3}}{3}\left(C_{0}-C_{e}\right)-\frac{8 R^{3}}{\pi}\left(C_{0}-C_{e}\right) \sum_{n=1}^{\infty} \frac{1}{n^{2}} \exp \left(-\left(\frac{n \pi}{R}\right)^{2} \frac{\xi t^{k}}{1+\beta t^{k}}\right)
$$

When the gas concentration in coal is $C_{e}$, the final desorbed gas volume is as follows:

$$
Q_{\infty}=\iiint_{v}\left(C_{0}-C_{e}\right) d V=\frac{4 \pi R^{3}}{3}\left(C_{0}-C_{e}\right)
$$

By dividing Equations (31) and (32), the following equation can be obtained:

$$
\frac{Q_{t}}{Q_{\infty}}=1-\frac{6}{\pi^{2}} \sum_{n=1}^{\infty} \frac{1}{n^{2}} \exp \left(-\frac{n^{2} \pi^{2}}{R^{2}} \frac{\xi t^{k}}{1+\beta t^{k}}\right)
$$

The effective diffusion coefficient can be expressed using the following equation:

$$
D_{D e}=\frac{D}{R^{2}}=\frac{A k t^{k-1}}{\left(1+\beta t^{k}\right)^{2}}
$$

where $A=\xi / R^{2}$ and $D_{D e}$ denotes the effective dynamic diffusion coefficient.

When the concentration on the surface of the coal matrix changes, the gas desorbs and diffuses. Combining Equations (33) and (34), the UDD model can be obtained as follows:

$$
\frac{Q_{t}}{Q_{\infty}}=1-\frac{6}{\pi^{2}} \sum_{n=1}^{\infty} \frac{1}{n^{2}} \exp \left(-n^{2} \pi^{2} \frac{A t^{k}}{1+\beta t^{k}}\right)
$$

\subsection{Method for Estimating the Diffusivity}

In this experiment, the final desorption amount was not measured as it would take a long time. As all the unipore, bidisperse and UDD models contain an infinite series, they were fitted using the Levenberg-Marquardt algorithm based on the iterative process [21]. However, if Equations (2), (5) and (35) were directly used to fit the diffusivity, the parameters $D_{a e}, D_{i e}, D_{e}, \lambda$, and $Q_{\infty}$ in the equation should be changed to adapt to the experimental data, leading to excessive parameterization and 
causing deviation. To eliminate this effect, the final desorption volume $Q_{\infty}$ was replaced by the total desorption volume in $9000 \mathrm{~s}$. Hence, the unipore model can be transformed as follows [22]:

$$
\frac{Q_{t}}{Q_{9000}}=\frac{Q_{t} / Q_{\infty}}{Q_{9000} / Q_{\infty}}=\frac{1-\frac{6}{\pi^{2}} \sum_{n=1}^{\infty} \frac{1}{n^{2}} \exp \left(-n^{2} t \pi^{2} D_{e}\right)}{1-\frac{6}{\pi^{2}} \sum_{n=1}^{\infty} \frac{1}{n^{2}} \exp \left(-9000 n^{2} \pi^{2} D_{e}\right)}
$$

The bidisperse model can be transformed as follows:

$$
\begin{gathered}
\frac{Q_{a t}}{Q_{a 9000}}=\frac{Q_{a t} / Q_{\infty}}{Q_{a 9000} / Q_{\infty}}=\frac{1-\frac{6}{\pi^{2}} \sum_{n=1}^{\infty} \frac{1}{n^{2}} \exp \left(-n^{2} t \pi^{2} D_{a e}\right)}{1-\frac{6}{\pi^{2}} \sum_{n=1}^{\infty} \frac{1}{n^{2}} \exp \left(-9000 n^{2} \pi^{2} D_{a e}\right)} \\
\frac{Q_{i t}}{Q_{i 9000}}=\frac{Q_{i t} / Q_{\infty}}{Q_{i 9000} / Q_{\infty}}=\frac{1-\frac{6}{\pi^{2}} \sum_{n=1}^{\infty} \frac{1}{n^{2}} \exp \left(-n^{2} t \pi^{2} D_{i e}\right)}{1-\frac{6}{\pi^{2}} \sum_{n=1}^{\infty} \frac{1}{n^{2}} \exp \left(-9000 n^{2} \pi^{2} D_{i e}\right)} \\
\frac{Q_{t}}{Q_{9000}}=\lambda \frac{Q_{a t}}{Q_{a 9000}}+(1-\lambda) \frac{Q_{i t}}{Q_{i 9000}}
\end{gathered}
$$

The UDD model can be transformed as follows:

$$
\frac{Q_{t} / Q_{\infty}}{Q_{9000} / Q_{\infty}}=\frac{Q_{t}}{Q_{9000}}=\frac{1-\frac{6}{\pi^{2}} \sum_{n=1}^{\infty} \frac{1}{n^{2}} \exp \left(-n^{2} \pi^{2} \frac{A t^{k}}{1+\beta^{k}}\right)}{1-\frac{6}{\pi^{2}} \sum_{n=1}^{\infty} \frac{1}{n^{2}} \exp \left(-n^{2} \pi^{2} \frac{A 9000^{k}}{1+\beta 9000^{k}}\right)}
$$

\section{Experiments}

\subsection{Coal Samples}

The coal samples used in this experiment were collected from the \#2 coal seam of Dongpang Coal Mine owned by the Jizhong Energy Group, Xingtai, China. After sampling, all coal samples were sealed and sent to the laboratory. Based on the Chinese national standards AQ/T1065-2008 and GB474-2008, after removing the surface oxide layer, the coal samples were crushed using a high-speed crusher, followed by grinding and screening to obtain the coal particles. The coal particles were divided into the following three categories in terms of size: (1) $0.25-0.5 \mathrm{~mm}$; (2) $0.5-1.0 \mathrm{~mm}$; and (3) $1.0-1.25 \mathrm{~mm}$. Table 2 presents the industrial analysis of the coal samples.

Table 2. Information of the coal samples.

\begin{tabular}{cccccccc}
\hline Mad $\%$ & Aad $\%$ & Ad $\%$ & Vad $\%$ & Vd $\%$ & Vdaf $\%$ & FCad $\%$ & FCd $\%$ \\
\hline 1.3 & 12.06 & 11.39 & 10.04 & 9.72 & 11.36 & 78.69 & 76.12 \\
\hline
\end{tabular}

\subsection{Experimental System}

Figure 4 shows the experimental system. An automatic desorption device was developed. Polypropylene resin pipes were used to collect gas. The micro air pump, desorption pipeline, and differential pressure sensor were connected through a valve. Using the micro air pump, the gas was extracted from the pipeline and the liquid level was increased. The sensor was used to measure the height of the liquid level. During desorption and gas collection, the sensor was used to depict the height of the liquid level in the gas collector and then calculate the gas collection volume. 


\subsection{Experimental Methods}

The experiments were conducted with three different particle sizes $(0.25-0.5,0.5-1.0$, and $1.0-1.25 \mathrm{~mm})$ under three different pressures $(0.5,1.0$, and $1.5 \mathrm{MPa})$, with $220 \mathrm{~g}$ of granular coal for each group. The specific steps are as follows:

(1) To avoid the impact of moisture, the three groups of coal samples with different particle sizes obtained by grinding and sieving were placed in an electrothermal isothermal drying box at $50{ }^{\circ} \mathrm{C}$ for $12 \mathrm{~h}$ to remove water from the coal. Then, the samples were put into the coal sample tank.

(2) Based on the experiment's requirements, after assembling the debugging equipment, the coal sample tank was put into an isothermal water bath, and the temperature was set to $298.15 \mathrm{~K}$ to maintain the experimental temperature in the range of $0.1 \mathrm{~K}$ and to keep the test temperature constant.

(3) The valve (Valve g) was opened between the reference tank and sample tank, and the air and other gas impurities were removed using a vacuum pump (until the vacuum meter reads $<10 \mathrm{~Pa}$ ).

(4) After vacuum degassing, Valve g was closed, and then $\mathrm{CH}_{4}$ was injected into the reference tank using a high-pressure $\mathrm{CH}_{4}$ cylinder, and the pressure relief valve was adjusted until the pressure of the reference tank was stabilized at $0.5 \mathrm{MPa}$. Then, Valve $\mathrm{g}$ was opened to allow $\mathrm{CH}_{4}$ into the sample tank. After the number on the pressure indicator was kept constant for $1 \mathrm{~h}$, the valve between the sample tank and the reference tank was disconnected to continue to fill $\mathrm{CH}_{4}$ into the reference tank until the pressure reached 0.5 MPa. Next, the valves of the reference and sample tanks were opened until adsorption equilibrium. Meanwhile, the pressure remained constant. The process was repeated until the pressure remained at $0.5 \mathrm{MPa}$ for $1 \mathrm{~h}$, and the sample was at $0.5 \mathrm{MPa}$ adsorption equilibrium pressure.

(5) Once equilibrium was attained, the automatic desorption instrument was turned on and the data acquisition system was activated for gas desorption. The desorption lasted for $9000 \mathrm{~s}$.

(6) After the experiment of the three groups of coal samples was completed under $0.5 \mathrm{MPa}$, the experiment was repeated under 1.0 and $1.5 \mathrm{MPa}$ until all desorption processes were completed.

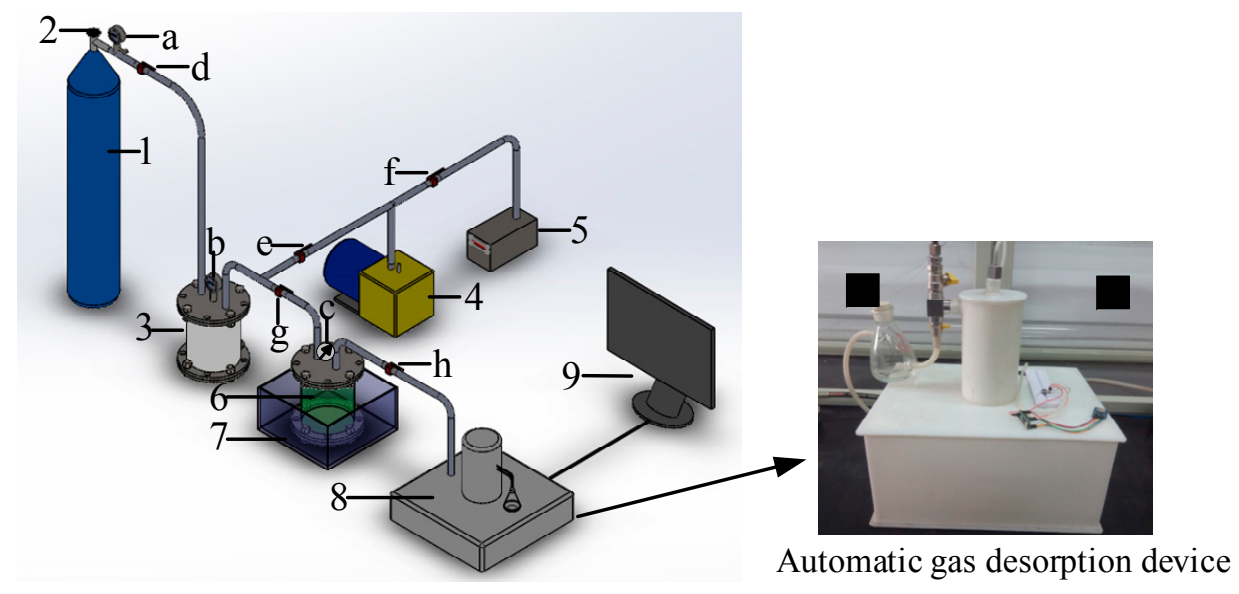

Figure 4. Gas desorption experiment system. (1) High pressure $\mathrm{CH}_{4}$ cylinder (99.9\% purity); (2) pressure reducing valve; (3) reference tank; (4) vacuum pump; (5) vacuum gauge; (6) coal sample tank; (7) constant temperature water bath; (8) automatic gas desorption instrument; (9) data collection system; $(a-c)$ pressure gauge; $(d-h)$ valve.

\section{Results}

\subsection{Desorbed Gas Volume}

Figure 5 shows the data of gas desorption for the different particle sizes and equilibrium pressures. The desorbed gas volume increased with time for the different particle sizes and pressures. 
However, the desorption rate decreased with time. At $9000 \mathrm{~s}$, the $0.25-0.5 \mathrm{~mm}$ coal samples under 1.5 MPa exhibited the largest desorbed gas volume $(4.61 \mathrm{~mL} / \mathrm{g})$, while the $1.0-1.25 \mathrm{~mm}$ coal samples under $0.5 \mathrm{MPa}$ showed the minimum desorbed gas volume (i.e., $0.78 \mathrm{~mL} / \mathrm{g}$ ), accounting for $47.8 \%$ and $29.6 \%$ of the desorbed gas volume under 0.5 and $1.0 \mathrm{MPa}$, respectively. Under the same pressure, taking $0.5 \mathrm{MPa}$ as an example, the desorbed gas volume of $1.0-1.25 \mathrm{~mm}$ coal samples accounted for $43.4 \%$ and $59.1 \%$ of the desorbed gas volume of $0.25-0.5 \mathrm{~mm}$ and $0.5-1.0 \mathrm{~mm}$ coal samples, respectively. In addition, Figure 5 shows that the desorbed gas volume negatively correlates with the particle size under the same pressure. However, with the same particle size, the pressure positively correlates with the desorbed gas volume because the gas concentration gradient increases with the equilibrium pressure. Furthermore, the desorbed gas volume was affected by both the particle size and pressure.

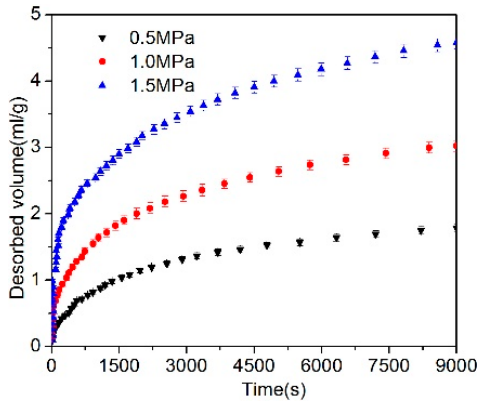

(a)

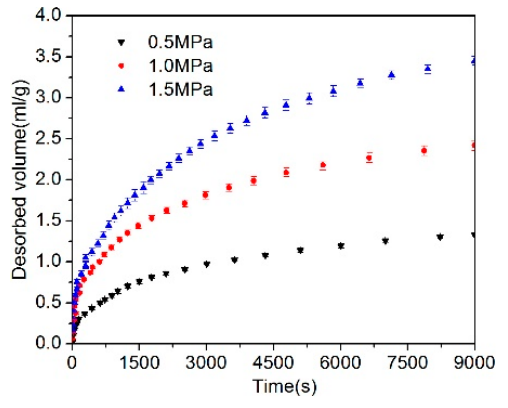

(b)

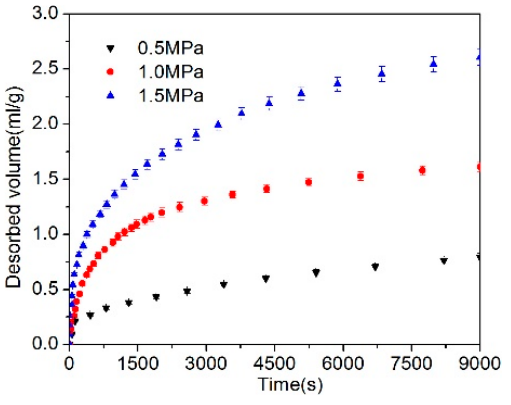

(c)

Figure 5. The variation of desorbed gas volume with time at different particle sizes and gas pressures (a) particle size is $0.25-0.5 \mathrm{~mm}$; (b) particle size is $0.5-1.0 \mathrm{~mm}$; (c) particle size is $1.0-1.25 \mathrm{~mm}$.

\subsection{Fitting Results of the Unipore Model and Bidisperse Model}

Based on Equations (36) and (39), the experimental data were fitted using the unipore and bidisperse models. Figure 6 shows the results. The $R^{2}$ value of the bidisperse model ranged $0.9974-0.9992$, which is much better than the unipore model. Tables 3 and 4 show the calculated constants. The diffusion coefficients of the unipore model and macropores and micropores in the bidisperse model were in the order of magnitude of $10^{-5} \mathrm{~s}^{-1}$. The diffusion coefficients of macropores ranged $2.51 \times 10^{-5} \mathrm{~s}^{-1}$ $5.56 \times 10^{-5} \mathrm{~s}^{-1}$, while the diffusion coefficients of micropores ranged $1.05 \times 10^{-5} \mathrm{~s}^{-1}-4.73 \times 10^{-5} \mathrm{~s}^{-1}$. All the diffusion coefficients of macropores were larger than the diffusion coefficients of micropores, which is consistent with Wang et al. [22]. The calculation results of both models revealed a negative correlation between the particle size and the diffusion coefficient. In addition, the fitting value $D_{e}$ of the diffusion coefficient in the unipore model positively correlated with gas pressure. However, in the bidisperse model, $D_{a e}$ and $D_{i e}$ of $0.25-0.5 \mathrm{~mm}$ and $0.5-1.0 \mathrm{~mm}$ coal samples increased with pressure, $D_{a e}$ of 1.0-1.25 mm coal samples increased first and then decreased with an increase of pressure, and $D_{i e}$ decreased first and then increased. Furthermore, the value of the diffusion characteristic parameter $\lambda$ in the bidisperse model ranged $0.745-0.830$, suggesting that the diffusion characteristic parameter is stable in the desorption process and that its intrinsic properties do not fluctuate markedly with the variation of the pressure and particle size.

\subsection{Fitting Results of the UDD Model}

Figure 7 and Table 5 show the fitting results and constants of the UDD model. The fitting results of the UDD model were excellent, with the $R^{2}$ values of gas diffusivity of all samples well above 0.999, which is better than the unipore and bidisperse models. Table 5 shows that the values of $A$ and $k$ increase with the decrease of the particle size, whereas the $\beta$ values have no significant dependence on the particle size, and the values of $k$ are $<1$. The order of magnitude of the $A$ value ranged $10^{-4}-10^{-5}$, which is roughly similar to the initial diffusion coefficient reported previously [23,24], and the value of $A$ is 1-3 orders of magnitude higher than $\beta$. Figure 8 shows the diffusion characteristics of the 
coal samples with three different particle sizes under three different pressures. The diffusivity of gas decreases rapidly in the early stage, and the diffusion coefficient decreases gradually to a flat level in the later stage. Under the same pressure, the particle size negatively correlated with the diffusion coefficient. For $0.25-0.5 \mathrm{~mm}$ and $0.5-1.0 \mathrm{~mm}$ coal samples, the dynamic diffusion coefficient $D_{D e}$ positively correlated with pressure, while for $1.0-1.25 \mathrm{~mm}$ coal samples, $D_{D e}$ increased first and then decreased with the increase of pressure.
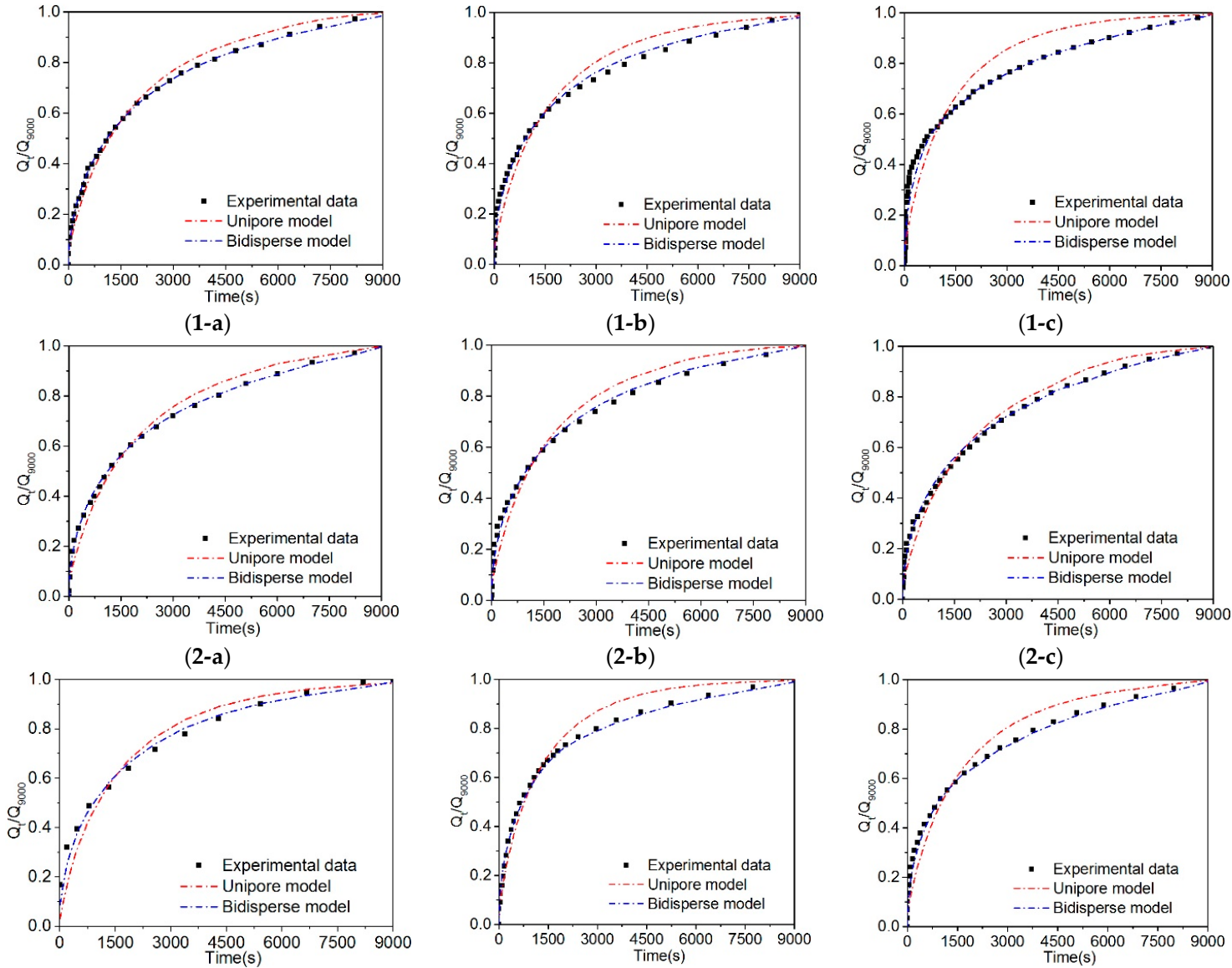

$(2-b)$
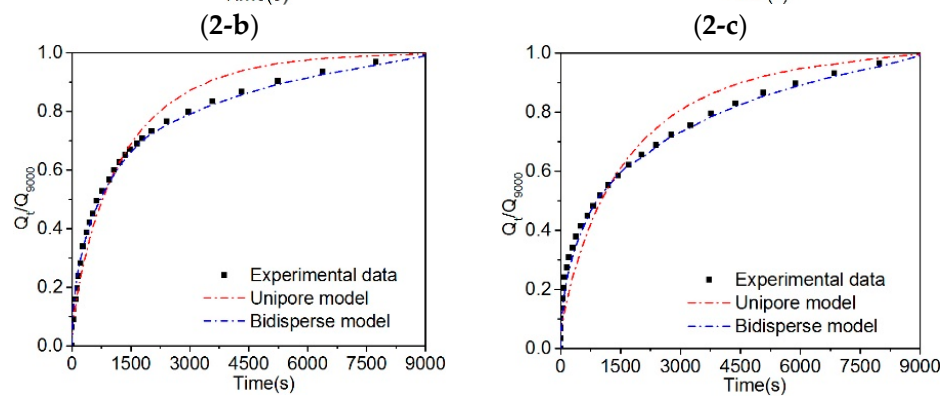

(3-b)

(3-c)

Figure 6. Fitting results of the unipore model and bidisperse model. (1-a) particle size:0.25-0.5 mm, gas pressure: $0.5 \mathrm{MPa}$; (1-b) particle size: $0.25-0.5 \mathrm{~mm}$, gas pressure: $1.0 \mathrm{MPa}$; (1-c) particle size: 0.25-0.5 mm, gas pressure: $1.5 \mathrm{MPa}$; (2-a) particle size: $0.5-1.0 \mathrm{~mm}$, gas pressure: $0.5 \mathrm{MPa}$; (2-b) particle size: $0.5-1.0 \mathrm{~mm}$, gas pressure: $1.0 \mathrm{MPa}$; (2-c) particle size: $0.5-1.0 \mathrm{~mm}$, gas pressure: $1.5 \mathrm{MPa}$; (3-a) particle size: $1.0-1.25 \mathrm{~mm}$, gas pressure: $0.5 \mathrm{MPa}$; (3-b) particle size:1.0-1.25 mm, gas pressure: 1.0 MPa; (3-c) particle size: $1.0-1.25 \mathrm{~mm}$, gas pressure: $1.5 \mathrm{MPa}$.

Table 3. Fitting results of the unipore model.

\begin{tabular}{ccccccc}
\hline Size (mm) & \multicolumn{2}{c}{$\mathbf{0 . 2 5} \mathbf{~ m m - 0 . 5 ~} \mathbf{~ m}$} & \multicolumn{2}{c}{$\mathbf{0 . 5} \mathbf{~ m m - 1 . 0 ~} \mathbf{~ m}$} & \multicolumn{2}{c}{$\mathbf{1 . 0} \mathbf{~ m m}-\mathbf{1 . 2 5} \mathbf{~ m m}$} \\
\hline Pressure (MPa) & $\left.\boldsymbol{D}_{\boldsymbol{e}} \mathbf{( s}^{\mathbf{- 1}}\right)$ & $\mathbf{R}^{\mathbf{2}}$ & $\boldsymbol{D}_{\boldsymbol{e}} \mathbf{( s}^{\mathbf{- 1}}$ & $\mathbf{R}^{\mathbf{2}}$ & $\boldsymbol{D}_{\boldsymbol{e}}\left(\mathbf{s}^{\mathbf{- 1}}\right)$ & $\mathbf{R}^{\mathbf{2}}$ \\
\hline $0.5 \mathrm{MPa}$ & $3.58 \times 10^{-05}$ & 0.9872 & $3.44 \times 10^{-05}$ & 0.9846 & $3.36 \times 10^{-05}$ & 0.9805 \\
$1.0 \mathrm{MPa}$ & $4.11 \times 10^{-05}$ & 0.9828 & $4.06 \times 10^{-05}$ & 0.9833 & $3.64 \times 10^{-05}$ & 0.9781 \\
$1.5 \mathrm{MPa}$ & $5.06 \times 10^{-05}$ & 0.9759 & $4.62 \times 10^{-05}$ & 0.9901 & $3.82 \times 10^{-05}$ & 0.9911 \\
\hline
\end{tabular}


Table 4. Fitting results of the bidisperse model.

\begin{tabular}{|c|c|c|c|c|c|c|c|c|c|c|c|c|}
\hline Size (mm) & & $0.25 \mathrm{~mm}-0$ & & & & $0.5 \mathrm{~mm}-1$. & & & & $1.0 \mathrm{~mm}-1.2$ & & \\
\hline Pressure (MPa) & $D_{a e}\left(\mathrm{~s}^{-1}\right)$ & $D_{i e}\left(\mathrm{~s}^{-1}\right)$ & $\eta$ & $\mathbf{R}^{2}$ & $D_{a e}\left(\mathrm{~s}^{-1}\right)$ & $D_{i e}\left(\mathrm{~s}^{-1}\right)$ & $\eta$ & $\mathbf{R}^{2}$ & $D_{a e}\left(\mathrm{~s}^{-1}\right)$ & $D_{i e}\left(\mathrm{~s}^{-1}\right)$ & $\eta$ & $\mathbf{R}^{2}$ \\
\hline $0.5 \mathrm{MPa}$ & $3.58 \times 10^{-05}$ & $2.96 \times 10^{-05}$ & 0.762 & 0.9989 & $2.75 \times 10^{-05}$ & $2.74 \times 10^{-05}$ & 0.789 & 0.9992 & $2.51 \times 10^{-05}$ & $1.21 \times 10^{-05}$ & 0.745 & 0.9988 \\
\hline 1.0 MPa & $3.92 \times 10^{-05}$ & $3.33 \times 10^{-05}$ & 0.816 & 0.9992 & $3.35 \times 10^{-05}$ & $2.62 \times 10^{-05}$ & 0.814 & 0.9974 & $3.23 \times 10^{-05}$ & $1.05 \times 10^{-05}$ & 0.769 & 0.9991 \\
\hline $1.5 \mathrm{MPa}$ & $5.56 \times 10^{-05}$ & $4.73 \times 10^{-05}$ & 0.830 & 0.9978 & $4.85 \times 10^{-05}$ & $2.70 \times 10^{-05}$ & 0.813 & 0.9987 & $3.01 \times 10^{-05}$ & $1.76 \times 10^{-05}$ & 0.738 & 0.9985 \\
\hline
\end{tabular}

Table 5. Fitting results of the UDD model.

\begin{tabular}{|c|c|c|c|c|c|c|c|c|c|c|c|c|}
\hline \multirow{2}{*}{$\begin{array}{c}\text { Size }(\mathrm{mm}) \\
\text { Pressure }(\mathrm{MPa})\end{array}$} & \multicolumn{4}{|c|}{$0.25 \mathrm{~mm}-0.5 \mathrm{~mm}$} & \multicolumn{4}{|c|}{$0.5 \mathrm{~mm}-1.0 \mathrm{~mm}$} & \multicolumn{4}{|c|}{$1.0 \mathrm{~mm}-1.25 \mathrm{~mm}$} \\
\hline & A & $\beta$ & $k$ & $R^{2}$ & A & $\beta$ & $k$ & $\mathbf{R}^{2}$ & A & $\beta$ & $k$ & $\mathbf{R}^{2}$ \\
\hline $0.5 \mathrm{MPa}$ & $3.99 \times 10^{-05}$ & $2.35 \times 10^{-06}$ & 0.878 & 0.9994 & $3.76 \times 10^{-05}$ & $1.28 \times 10^{-07}$ & 0.854 & 0.9998 & $3.43 \times 10^{-05}$ & $1.37 \times 10^{-06}$ & 0.721 & 0.9997 \\
\hline 1.0 MPa & $5.68 \times 10^{-05}$ & $2.59 \times 10^{-07}$ & 0.869 & 0.9996 & $4.43 \times 10^{-05}$ & $8.28 \times 10^{-04}$ & 0.822 & 0.9995 & $4.11 \times 10^{-05}$ & $2.76 \times 10^{-07}$ & 0.802 & 0.9996 \\
\hline $1.5 \mathrm{MPa}$ & $1.29 \times 10^{-04}$ & $2.12 \times 10^{-05}$ & 0.878 & 0.9991 & $4.89 \times 10^{-05}$ & $3.64 \times 10^{-08}$ & 0.851 & 0.9992 & $3.94 \times 10^{-05}$ & $5.89 \times 10^{-05}$ & 0.801 & 0.9994 \\
\hline
\end{tabular}




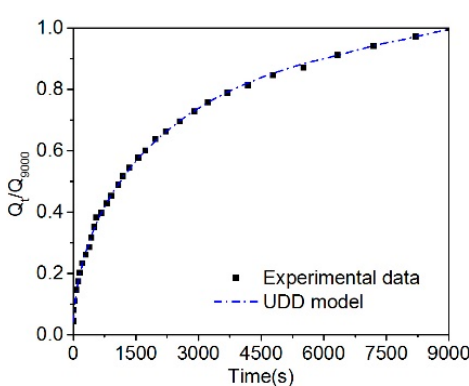

(1-a)

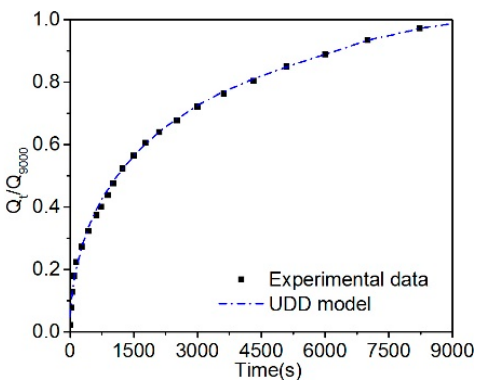

(2-a)

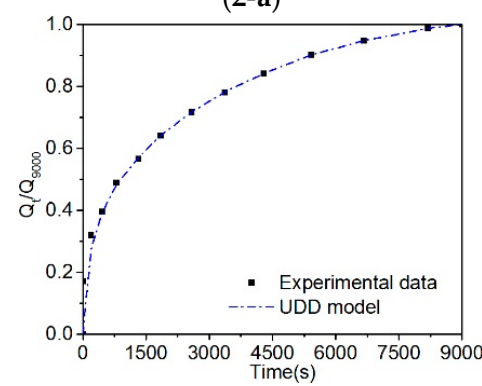

(3-a)

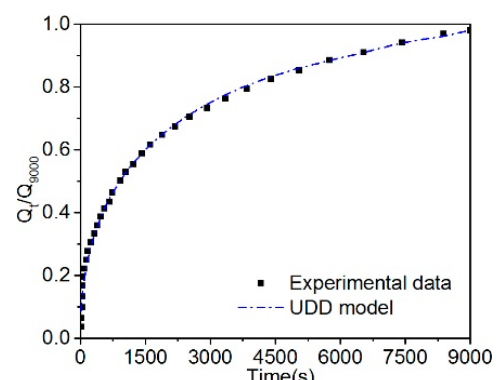

(1-b)

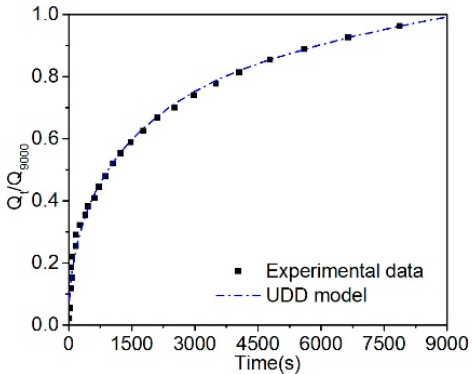

(2-b)

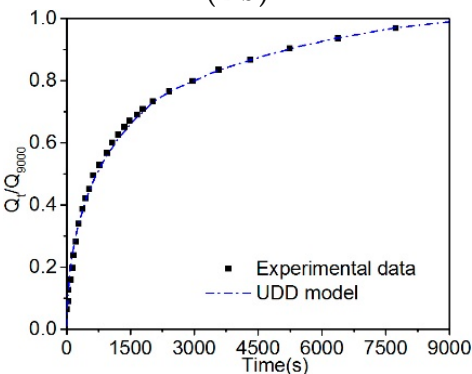

(3-b)

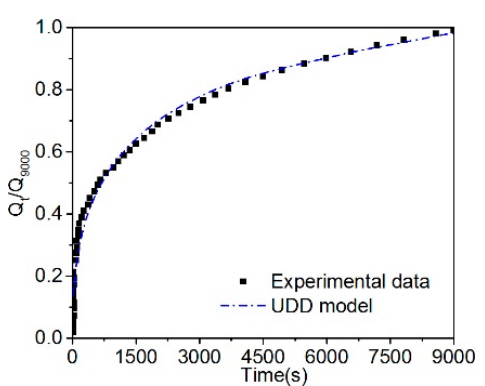

(1-c)

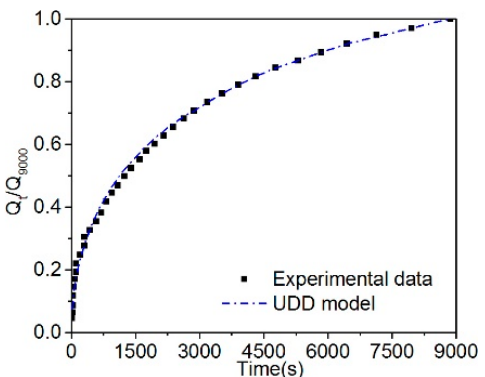

(2-c)

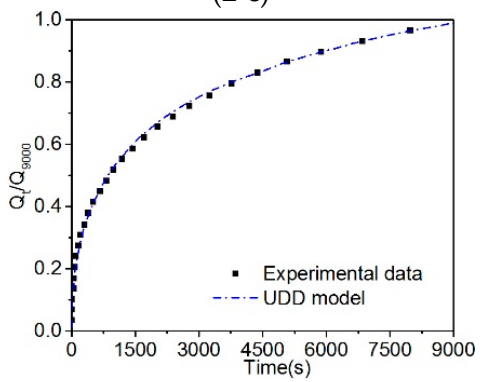

(3-c)

Figure 7. Fitting results of the unsteady dynamic diffusion (UDD) model. (1-a) particle size: 0.25-0.5 mm, gas pressure: $0.5 \mathrm{MPa}$; (1-b) particle size: $0.25-0.5 \mathrm{~mm}$, gas pressure: $1.0 \mathrm{MPa}$; (1-c) particle size: 0.25-0.5 mm, gas pressure: $1.5 \mathrm{MPa}$; (2-a) particle size: $0.5-1.0 \mathrm{~mm}$, gas pressure: $0.5 \mathrm{MPa}$; (2-b) particle size: $0.5-1.0 \mathrm{~mm}$, gas pressure: $1.0 \mathrm{MPa}$; (2-c)particle size: $0.5-1.0 \mathrm{~mm}$, gas pressure: $1.5 \mathrm{MPa}$; (3-a) particle size: $1.0-1.25 \mathrm{~mm}$, gas pressure: $0.5 \mathrm{MPa}$; (3-b) particle size:1.0-1.25 mm, gas pressure: 1.0 MPa; (3-c)particle size: $1.0-1.25 \mathrm{~mm}$, gas pressure: $1.5 \mathrm{MPa}$.

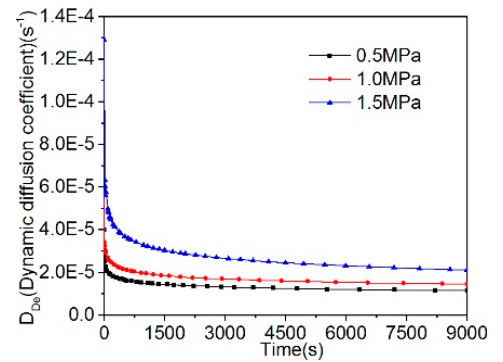

(a)

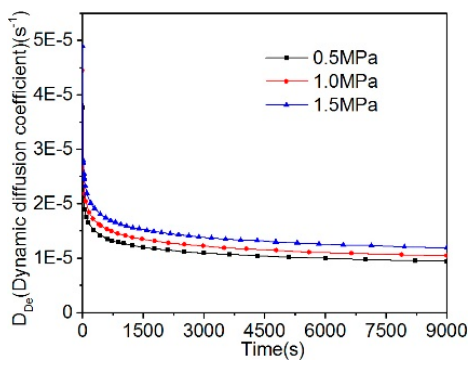

(b)

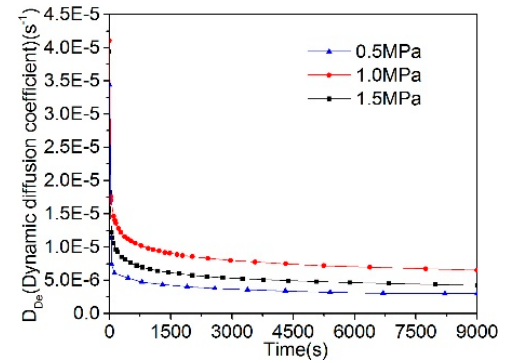

(c)

Figure 8. Dynamic diffusion coefficient based on the UDD Model $\left(D_{D e}\right)(\mathbf{a})$ particle size: $0.25-0.5 \mathrm{~mm}$;

(b) particle size 0.5-1.0 mm; (c) particle size: $1.0-1.25 \mathrm{~mm}$.

\section{Discussion}

\subsection{Comparison of the Unipore, Bidisperse, and UDD Models}

The unipore and bidisperse models have been extensively used in the calculation of the gas diffusion coefficient in coal [14]. From a mathematical perspective, the unipore model does not 
adequately capture the sorption kinetics, and the bidisperse model has better fitting results than the unipore model. Staib et al. reported that it was inaccurate to explain diffusion with one parameter. Using the bidisperse model, a study described the diffusion behavior of $\mathrm{CO}_{2}$ under different pressures and reported good fitting results [25]. Siemons et al. investigated the diffusion behavior of $\mathrm{CO}_{2}$ in coal and revealed that the bidisperse model had a good fitting effect [5]. Pan et al. investigated the diffusion behavior of $\mathrm{CH}_{4}$ in coal with different moistures and reported a good fitting effect of the bidisperse model [12]. Clarkson and Bustin believed that, regarding the applicability of the model, the pore structure of coal should be considered [8]. They suggested that the unipore model was suitable for coals with a simple pore structure (as its hypothesis was that the pores had a spherical and homogeneous structure), while the bidisperse model was more suitable for coals with a complex structure.

According to Figure 7 and Table 5, the fitting effect of the UDD model was slightly better than the bidisperse model, and all the values of $R^{2}$ were $>0.999$. However, the residual between the model fitting data and experimental data could well evaluate the fitting quality of different models under different conditions (equilibrium pressure and particle size) relative to the experimental data [26]. Figure 9 shows that the residual range of the UDD model is lower than the bidisperse and unipore models, suggesting that the UDD model could well describe the gas diffusion behavior in coal.
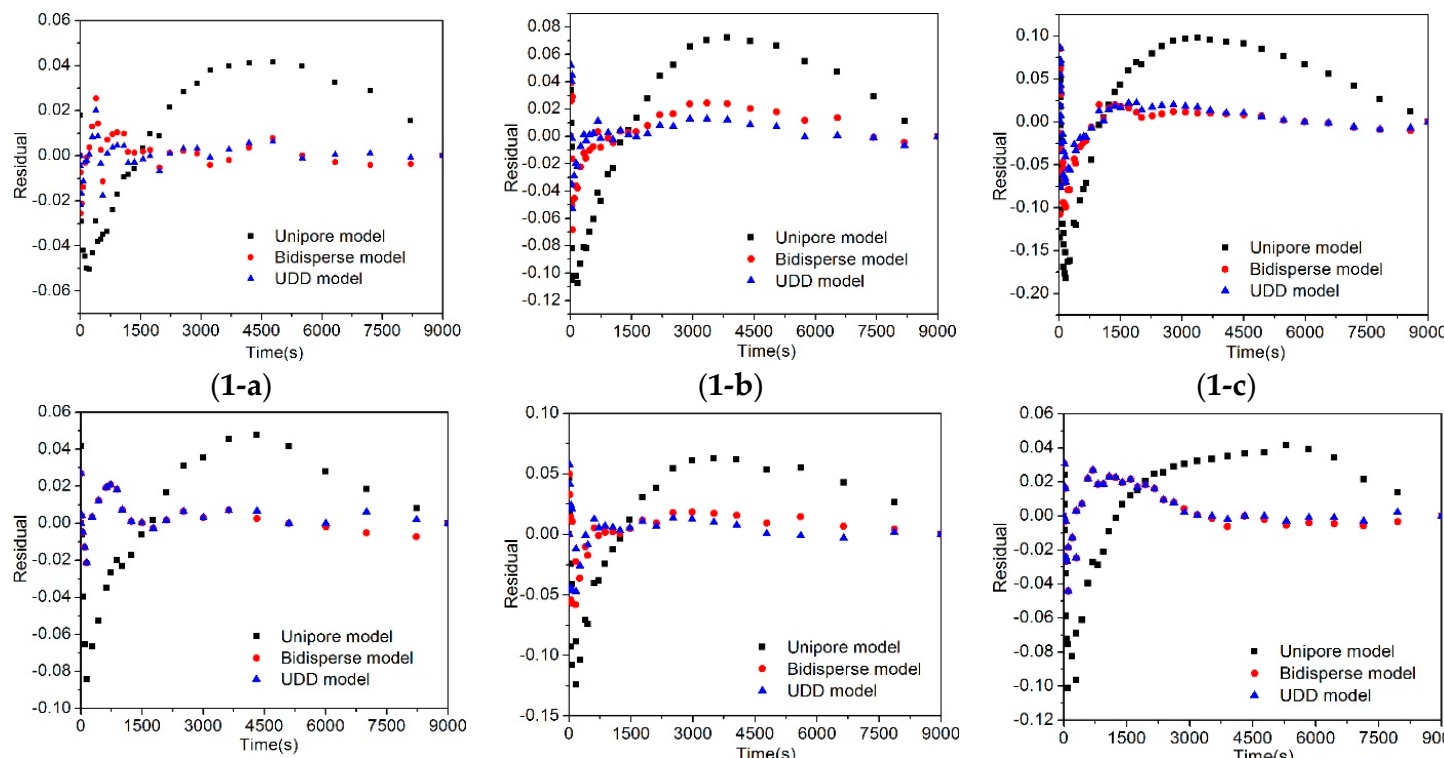

$(1-b)$

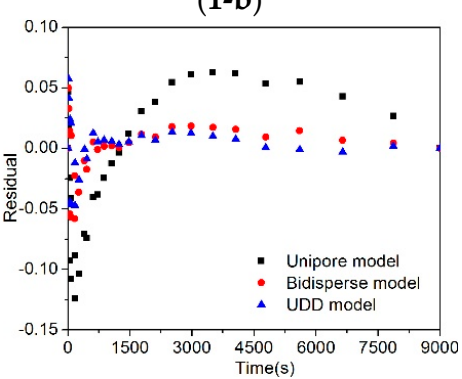

$(1-\mathrm{c})$

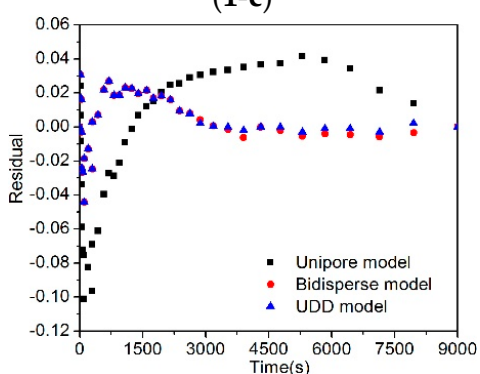

(2-a)
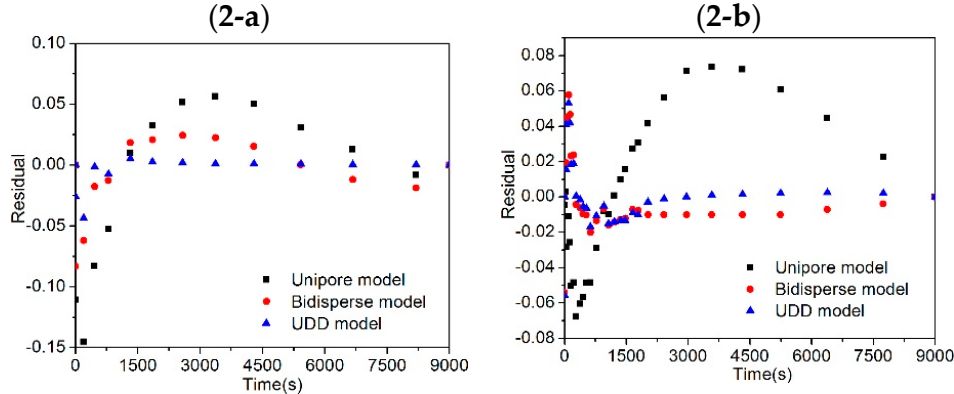

(3-a)

(3-b)

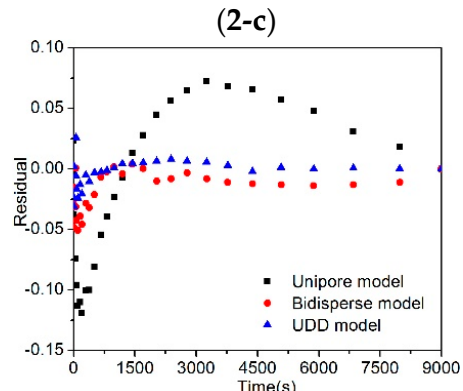

(3-c)

Figure 9. Residual comparing the unipore, bidisperse, and UDD models. (1-a) particle size: 0.25-0.5 mm, gas pressure: $0.5 \mathrm{MPa}$; (1-b) particle size: $0.25-0.5 \mathrm{~mm}$, gas pressure: $1.0 \mathrm{MPa}$; (1-c) particle size: 0.25-0.5 mm, gas pressure: $1.5 \mathrm{MPa}$; (2-a) particle size: $0.5-1.0 \mathrm{~mm}$, gas pressure: $0.5 \mathrm{MPa}$; (2-b) particle size: $0.5-1.0 \mathrm{~mm}$, gas pressure: $1.0 \mathrm{MPa}$; (2-c) particle size: $0.5-1.0 \mathrm{~mm}$, gas pressure: $1.5 \mathrm{MPa}$; (3-a) particle size: $1.0-1.25 \mathrm{~mm}$, gas pressure: $0.5 \mathrm{MPa}$; (3-b) particle size:1.0-1.25 mm, gas pressure: 1.0MPa; (3-c) particle size: $1.0-1.25 \mathrm{~mm}$, gas pressure: $1.5 \mathrm{MPa}$. 
The unipore and bidisperse models assume that the diffusion coefficient $D$ is constant, while in the UDD model, it is considered as a function of time. Zhao et al. demonstrated that the gas concentration, position, and time were key factors affecting the diffusion coefficient and concluded that the assumption of a constant diffusion coefficient was inaccurate and could deviate the results [27]. Zhang proposed that analytic solutions could not be obtained using the unipore and bidisperse models based on Fick's law if the impact of the concentration and position $x$ on diffusion were considered [28]. The diffusion coefficient as a function of time $t$ could be attributed to the following two reasons: (a) The impact of the concentration change; and (b) the collision with the pore wall during molecular diffusion might cause kinetic energy loss [29-31]. The dynamic diffusion coefficient evaluated using the UDD model (Figure 8) revealed that the diffusion coefficient of gas decreased rapidly in the early stage and gradually decreased to a flat level in the later stage. Thus, it significantly negatively correlated with time, which is similar to Guo et al. [24]. This study explored the underlying reasons based on the different mechanisms. Liu et al. studied the dynamic diffusion behavior of $\mathrm{CO}_{2}$ in coal and believed that the continuous decrease of the diffusion concentration could result in a negative time-dependent correlation of the diffusion coefficient [32], which was consistent with the findings of Nandi and Walker [7]. Nandi and Walker argued that the desorbed gas volume positively correlated with $D$ [7]. In addition, the pore structure was considered to be another major factor affecting gas diffusion. Liu et al. reasoned that the pressure decreased during the desorption of $\mathrm{CH}_{4}$, and the pores expanded because adsorption would narrow gradually. Thus, the diffusion resistance would increase, and the diffusion coefficient would, therefore, decrease progressively [19]. In addition, Li et al. observed the same phenomenon but they believed that the gas diffused primarily through the macropore of the coal matrix in the early stage, and gradually through the micropore in the later stage. Thus, the diffusion coefficient gradually decreased with time [20]. Section 2.3.1 explained that for the dynamic diffusion characteristics of the UDD model, the pore differential diffusivity connected to the main diffusion path was mainly considered. First, the main diffusion path was occupied by the gas desorbed through the pores with a larger throat. Based on Fick's law, the diffusion primarily depended on the concentration gradient. Thus, in the initial stage of diffusion, the diffusion in the pore with a narrow throat was affected by high-concentration gas in the main diffusion path. Hence, the gas first diffused through the macropore on the coal surface, then through the well-connected pore, and finally through the poorly connected pore. As the pore connectivity deteriorated, the diffusion resistance increased, leading to the decay of the diffusion coefficient. Moreover, the entire process of diffusion could be simulated on the basis of the UDD model. While early gas diffusion coefficients were underestimated, late gas diffusion coefficients were overestimated by using constant coefficient diffusion models (unipore and bidisperse models). As explained in Section 2.3.1, the gas diffusion behavior is affected by the pore gas concentration in the different structures and the gas concentration difference in the main diffusion path as the desorption progresses, which could reasonably explain why the constant diffusion coefficient underestimates the desorption content at an earlier time, and the diffusion coefficient is overestimated at a later stage (Figure 10 provides evidence for this). Furthermore, the difference in the specific surface area of the different pores is accountable for the time-dependent characteristic of gas diffusion [33], explaining why the UDD model could simulate the entire gas diffusion process.

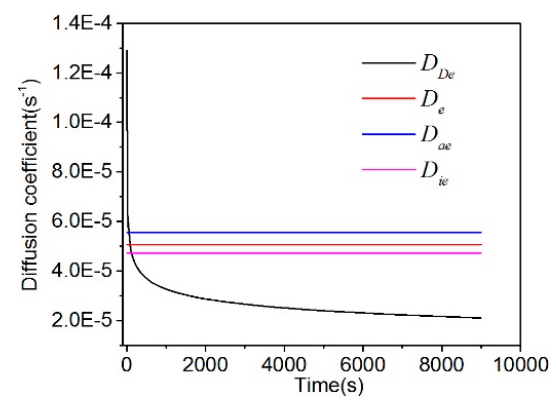

Figure 10. Comparison of $D_{D e}, D_{e}, D_{a e}$ and $D_{i e}$ (particle size: $0.25-0.5 \mathrm{~mm}$, gas pressure: $1.5 \mathrm{MPa}$ ). 
The diffusion ratio estimates (Figures 6 and 7) revealed that the experimental and fitting curves were not well matched. Besides, the Joule-Thomson effect is a major source, except for the reason of the time/pressure-dependent diffusion coefficient. The Joule-Thomson effect is the change in temperature of a gas on expansion through a porous plug from high pressure to a lower one under adiabatic conditions, especially for non-ideal gases, such as $\mathrm{CO}_{2}$ [34]. Thus, the Joule-Thomson effect is caused by the deviation of real gas from ideal gas. It is usually expressed by the Joule-Thomson coefficient, and the Joule-Thomson coefficient of gas varies with pressure. Microcracks and heterogeneity are crucial for oil and gas production. Jia et al. assessed the impact of the permeability and location of microcracks on the pulse-decay experiment based on numerical calculations [35]. The pulse-decay experiments by flowing helium under the different pressures revealed that the preferential flow path of gas could be found even without the microcracks. Thus, it is believed that the early pressure effect would result in a marked underestimation of the porosity, diffusion coefficient and permeability, and the preferential flow path would be more apparent in heterogeneous porous media under high pore pressure. To avoid the impact of the porosity, diffusion coefficient, and permeability and identify the preferential flow path, Jia et al. [35] suggested that the early pressure response should be closely examined in a pulse-decay experiment.

\subsection{Effect of Particle Size on the Diffusion Coefficient}

The fitting results of the diffusion coefficients $\left(D_{e}, D_{a e}, D_{i e}\right.$, and $\left.D_{D e}\right)$ of the three models (Tables 3 and 4; Figure 8) revealed that the diffusion coefficients decreased with an increase of the particle size, which could be attributed to the increase of the macropore volume in the grinding and screening process of smaller particles. Based on LP- $\mathrm{N}_{2} \mathrm{GA}$, Guo et al. conducted an experimental study on the pore size distribution in the coal matrix and believed that the pore structure in coal became simpler during grinding and screening, which shortened the path of gas diffusion and, thus, decreased the resistance of the diffusion [36]. Nandi and Walker believed that after coal particles were grinded, the total pore volume and specific surface area of pulverized coal increased with a decrease of the particle size, and an increase of the pore volume led to the increase of the diffusion coefficient [37]. However, different opinions have been proposed. It was highlighted that as the particle size decreases, the pore surface area increases, and the average pore width decreases. Consequently, the diffusion length is limited by the spatial dimensions of the holes, which results in a reduction in the effective diffusion area [38]. Moreover, studies have reported a limit of particle size in the desorption and diffusion of gases in the coal matrix. When the coal particle size decreases within the limit particle size range, both the gas diffusivity and decay coefficient would decrease. However, when the coal particle size is bigger than the limit particle size, the change of gas diffusivity is very small irrespective of the particle size increase or decrease [39].

\subsection{Effect of Gas Pressure on the Diffusion Coefficient}

Tables 3 and 4 and Figure 8 show that, based on the results of the unipore model, the diffusion coefficients of the coal samples with three particle sizes increased gradually under $0.5,1.0$, and $1.5 \mathrm{MPa}$, suggesting a positive correlation with pressure. In the bidisperse and UDD models, $D_{a e}, D_{i e}$, and the dynamic diffusion coefficient $D_{D e}$ of $0.25-0.5 \mathrm{~mm}$ and $0.5-1.0 \mathrm{~mm}$ coal samples increased with an increase of pressure, suggesting a positive correlation with pressure.

On the one hand, the increase of gas pressure decreased the average free path of gas molecules, and the diffusion coefficient increased. In addition, the increase of gas pressure would increase the gas adsorption volume of the pores, and the coal matrix expansion would shorten the gas diffusion path, resulting in a decrease of diffusion resistance and increase of the diffusion coefficient in the end. This phenomenon suggested that the coal seam with high gas pressure might become a favorable area for gas drainage and CBM development. Yue et al. investigated the diffusion behavior of gases in coal and demonstrated that with an increase of pressure, the interfacial mass transfer resistance decreased, and the diffusion coefficient and Fourier mass transfer criterion increased [40]. 
The pressure environment changed the kinetic parameters of coal desorption and increased the volume and rate of $\mathrm{CH}_{4}$ desorption, which was conducive to the desorption and diffusion of $\mathrm{CH}_{4}$ in coal. However, for 1.0-1.25 mm coal samples, the $D_{a e}$ and $D_{D e}$ increased first and then decreased with an increase of pressure, exhibiting no significant pressure dependence, which is consistent with Nandi [37]. Similar results were reported by Yang and Liu [41]. In particular, the diffusion coefficients under different pressures $(0.55-8.07 \mathrm{MPa})$ for the four tested coal samples were estimated using the unipore model. The findings revealed that the diffusion coefficient negatively correlated with the gas pressure when the gas pressure was $>2.48 \mathrm{MPa}$. Yang and Liu [41] believed that the decreasing trend corroborated the theoretical bulk diffusion coefficients and that the bulk diffusion coefficients depended on the gas pressure and the mean free path of the gas molecule. When the pressure was $<2.48 \mathrm{MPa}$, the diffusion coefficient positively correlated with the gas pressure. According to Wang and Liu, gas pressure increments opened the closed pores and, thus, more gas pathways were created to enhance the gas diffusion flow [42]. Moreover, the contributions of Knudsen diffusions and bulk diffusions in the gas flow process vary with pressure. The Knudsen diffusion impact is weakened as the gas pressure increases and the molecular collision intensifies. In addition, the bulk diffusions become critical under high pressure. Usually, Knudsen diffusions are slower than the bulk diffusions, resulting in a positive correlation between the diffusion coefficient and pressure when pressure is $<2.48 \mathrm{MPa}$. Yang et al. used the bidisperse model to fit the diffusion coefficients of adsorption and desorption at different pressures. They found that the effective diffusion coefficient $D_{e}$ first decreased and then increased with pressure [17]. Hence, there might be a critical pressure after which the pressure dependence of the effective diffusion coefficient experiences different changes. Sun conducted experiments on the diffusion of $\mathrm{CH}_{4}$ and $\mathrm{CO}_{2}$ in the coal samples from four different regions and fitted the results using the unipore model. The results showed that the gas diffusion coefficient was not pressure dependent under $5 \mathrm{MPa}$. However, a positive correlation existed when the pressure was $>5 \mathrm{MPa}$ [10]. Jia et al. conducted nearly 40 pressure pulse transmission tests to study the transmission mechanism of shale gas reservoirs under low- and high-pressure conditions and compared the results with that of $\mathrm{CO}_{2}$, helium $(\mathrm{He})$, and nitrogen $\left(\mathrm{N}_{2}\right)$ [43]. However, the adsorption capacity of $\mathrm{CO}_{2}$ and $\mathrm{N}_{2}$ was measured using the Gibbs adsorption method and the absolute adsorption method. The results revealed that the apparent porosity was markedly increased because of adsorption. The apparent porosity and the Gibbs/excess adsorption of $\mathrm{CO}_{2}$ continued to decrease over the entire pressure range and decreased sharply above the critical pressure, which is contrary to the change of $\mathrm{N}_{2}$. Of note, the apparent permeability of helium is the highest among the three types of gases, and the difference in permeability between $\mathrm{CO}_{2}$ and $\mathrm{N}_{2}$ is more significant with the increase of pressure, which is consistent with the trend of the mean free path and the Knudsen number. In the high-pressure phase-change region, the apparent porosity and apparent permeability of $\mathrm{CO}_{2}$ declined markedly. In the adsorption phase, the apparent porosity was significantly increased, as measured by the pulse-decay experiment. It exerted a positive impact on low-pressure $\mathrm{CO}_{2}$ permeability but a negative impact on high-pressure $\mathrm{CO}_{2}$ permeability. A study investigated the impact of adsorption nonlinearity on the estimation of the diffusion parameters and reported that the diffusion parameters of linear and nonlinear adsorption were different [44]. Nandi and Walker proposed that the pressure dependence of the diffusion coefficients based on the unipore model was because of the nonlinearity of the isotherms [37], which was supported by Ciembroniewicz and Marecka [45], Charrire et al. [2], and Smith and Williams [46]. An assumption of the unipore model is that the pores have a spherical and homogeneous structure. Before modeling the internal structure of coal, consideration should be given to better illustrate the heterogeneous structure of coal, such as through the bidisperse model. Some studies have reported a negative correlation between the pressure and diffusion coefficient $[9,47,48]$, suggesting that the inverse correlation between the gas molecular diffusion and pressure was because of the increase of resistance to the flow caused by the collision between molecules and the molecular diffusion was primarily through macropores. Likewise, Cui et al. proposed that the decrease of the $\mathrm{CO}_{2}$ diffusion coefficient with pressure correlated with the mass flow of expansion and contraction [11]. In particular, the different diffusion models 
might have different pressure dependences, even when the same experimental data are used [8,25]. To date, the pressure dependence of gas diffusion remains unclear. As the results could be affected by experimental conditions, the diffusion models, and so on, further studies are warranted.

\subsection{Meanings of the A, $\beta$, and $K$ in the UDD Model}

In a study, different models were used to elucidate the functional correlation between the diffusion coefficient and time [26]. Usually, two or more parameters were set in these models, one of which was the initial diffusion coefficient, and the other was the parameter that controlled the decay of the diffusion coefficient. The UDD model supported the condition well.

Based on the calculation results of Equation (34) and Table 5, the initial effective coefficient in the UDD model was approximately $\mathrm{A} k t^{k-1}$ as $\beta<1$. Combining the initial conditions and calculation results, $k$ was between 0 and 1 , so there should be a time when $\mathrm{A} k t^{k-1}=1$ in the first second of the initial diffusion. Hence, $A$ in the UDD model could be considered as the initial diffusion coefficient of the dynamic diffusion model.

Figure 8 shows that the dynamic diffusion coefficient decreases with time, and the changes in the values of $\beta$ and $k$ are significant in Table 5. To better determine the impact of the two constants on the decay of the diffusion coefficient, this study tested two datasets. In the first group, the effects of the different $\beta$ values on the variation of the gas diffusion coefficients were assessed by keeping the $A$ and $k$ values constant. In the second group, $A$ and $\beta$ values were kept constant to analyze the impact of the $k$ value on the dynamic diffusion coefficient (Figure 11a,b). Figure 11a shows a negative correlation between the $\beta$ value and the gas diffusion coefficient, and as time increases, the diffusion coefficient decays faster as $\beta$ decreases. Figure $11 \mathrm{~b}$ shows that the $k$ value correlates positively with the gas diffusion coefficient and exerts a great impact on the first half of the diffusion process. Furthermore, the attenuation effect is weakened with the increase of time. Table 5 shows that the particle size and $k$ value correlate negatively. However, the $\beta$ and $k$ values are not markedly dependent on pressure. Gas diffusion is affected by several factors, including moisture, temperature, and gas type. Hence, a wider range of experimental studies are warranted in the future to establish the significance of these hypotheses and constants.

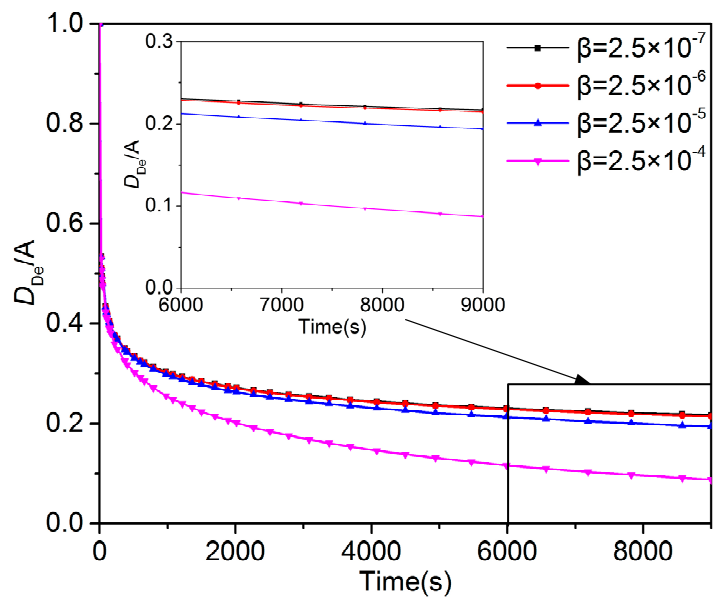

(a)

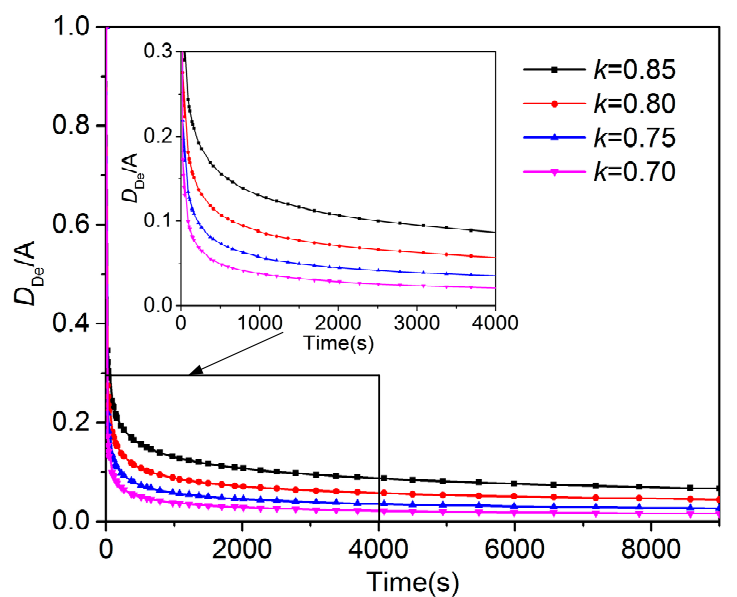

(b)

Figure 11. The relationship between the $D_{D e}$ and the constant $k$ and $\beta$ (a) different values of $\beta$, $\mathrm{A}=1.29 \times 10^{-4}, k=0.878$. (b) different values of $k, \mathrm{~A}=1.29 \times 10^{-4}, \beta=2.12 \times 10^{-5}$.

\section{Conclusions}

This study demonstrates that different pore structures and pore connectivity lead to different gas diffusion resistances, which result in the time dependence of the diffusion coefficient. The conclusions of this study are as follows: 
(1) Compared with the unipore model, the bidisperse and UDD models could better describe gas diffusion in coal, and the fitting effect of the UDD model is better than the bidisperse model. In addition, the UDD model could well simulate the entire diffusion process and illustrate the dynamic attenuation characteristics of the gas diffusion process. The diffusion coefficients of the three models are in the order of magnitude of $10^{-4} \mathrm{~s}^{-1}-10^{-6} \mathrm{~s}^{-1}$.

(2) Based on the calculation results of the diffusion coefficients $\left(D_{e}, D_{a e}, D_{i e}\right.$, and $\left.D_{D e}\right)$ of the three models, the effective diffusion coefficients of gases decrease with the increase of the particle size.

(3) In the unipore model, the diffusion coefficients of the coal samples with three particle sizes exhibited a positive correlation with pressure. In the bidisperse and UDD models, based on the calculation results of the diffusion coefficients $D_{i e}, D_{a e}$, and $D_{D e}$, the diffusion coefficients of $0.25-0.5 \mathrm{~mm}$ and $0.5-1.0 \mathrm{~mm}$ coal samples increase with the increase of pressure, exhibiting a positive correlation with pressure. In addition, $D_{D e}$ and $D_{a e}$ of $1.0-1.25 \mathrm{~mm}$ coal samples increase first and then decreased with the increase of pressure. However, $D_{i e}$ decreases first and then increases, suggesting no significant pressure dependence.

(4) This study discussed the significance of the parameters in the UDD model. While $A$ can be regarded as the initial diffusion coefficient, $\beta$ and $k$ can be regarded as the parameters controlling the decay of the diffusion coefficient. A negative correlation exists between $\beta$ and the gas diffusion coefficient, suggesting that a smaller $\beta$ value exerts a greater impact on the decay of the diffusion coefficient. Furthermore, $k$ positively correlates with the gas diffusion coefficient, suggesting that a larger $k$ value exerts a greater effect on the decay of the diffusion coefficient.

Author Contributions: Conceptualization, C.L.; Methodology, Y.N. Investigation, J.T.; Software, Y.Z.; Validation, X.Z. Funding: This research was funded by the National Natural Science Foundation of China $(51274206,51404277)$.

Conflicts of Interest: The authors declare that there are no conflicts of interest.

\section{References}

1. Alireza, K.; Richard, S.; Mihaela, G.; Sayyafzadeh, M. Effect of maceral composition and coal rank on gas diffusion in Australian coals. Int. J. Coal Geol. 2017, 173, 65-75.

2. Charrière, D.; Pokryszka, Z.; Behra, P. Effect of pressure and temperature on diffusion of $\mathrm{CO}_{2}$ and $\mathrm{CH}_{4}$ into coal from the Lorraine basin (France). Int. J. Coal Geol. 2010, 81, 373-380. [CrossRef]

3. Martina, S.; Zuzana, W.; Oldřich, P. The effect of moisture on the sorption process of $\mathrm{CO}_{2}$ on coal. Fuel 2012, 92, 187-196.

4. Zhang, J. Experimental Study and Modeling for $\mathrm{CO}_{2}$ Diffusion in Coals with Different Particle Sizes: Based on Gas Absorption (Imbibition) and Pore Structure. Energy Fuels 2016, 30, 531-543. [CrossRef]

5. Siemons, N.; Wolf, K.-H.A.; Bruining, J. Interpretation of carbon dioxide diffusion behavior in coals. Int. J. Coal Geol. 2007, 72, 315-324. [CrossRef]

6. Guo, H.; Cheng, Y.; Ren, T.; Wang, L.; Yuan, L.; Jiang, H.; Liu, H. Pulverization characteristics of coal from a strong outburst-prone coal seam and their impact on gas desorption and diffusion properties. J. Nat. Gas Sci. Eng. 2016, 33, 867-878. [CrossRef]

7. Nandi, S.; Walker, P. Activated diffusion of methane in coal. Fuel 1970, 49, 309-323. [CrossRef]

8. Clarkson, C.; Bustin, R. The effect of pore structure and gas pressure upon the transport properties of coal: A laboratory and modeling study. 2. Adsorption rate modeling. Fuel 1999, 78, 1345-1362. [CrossRef]

9. Pone, J.D.N.; Halleck, P.M.; Mathews, J.P. Sorption Capacity and Sorption Kinetic Measurements of $\mathrm{CO}_{2}$ and $\mathrm{CH}_{4}$ in Confined and Unconfined Bituminous Coal. Energy Fuels 2009, 23, 4688-4695. [CrossRef]

10. Sun, Y. Investigation of Gas Adsorption and Diffusion Behavior Based on Three-Dimensional Pore Structure of Coal; China University of Mining and Technology: Beijing, China, 2018. (In Chinese)

11. Cui, X.; Bustin, R.; Dipple, G. Selective transport of $\mathrm{CO}_{2}, \mathrm{CH}_{4}$, and $\mathrm{N}_{2}$ in coals: Insights from modeling of experimental gas adsorption data. Fuel 2004, 83, 293-303. [CrossRef]

12. Pan, Z.; Connell, L.D.; Camilleri, M.; Connelly, L. Effects of matrix moisture on gas diffusion and flow in coal. Fuel 2010, 89, 3207-3217. [CrossRef] 
13. Crank, J. The Mathematics of Diffusion, 2nd ed.; Oxford University Press: London, UK, 1975.

14. Ruckenstein, E.; Vaidyanathan, A.S.; Youngquist, G.R. Sorption by solids with bidisperse pore structure. Chem. Eng. Sci. 1971, 26, 1305-1318. [CrossRef]

15. Pramod, T. Chapter 4: Diffusion of Gases from Coal. In Advanced Reservoir and Production Engineering for Coal Bed Methane; Gulf Professional Publishing: Houston, TX, USA, 2017; pp. 51-59.

16. Wang, $\mathrm{K}$.; Wang, G.; Ren, T.; Cheng, Y. Methane and $\mathrm{CO}_{2}$ sorption hysteresis on coal: A critical review. Int. J. Coal Geol. 2014, 132, 60-80. [CrossRef]

17. Yang, X.; Wang, G.; Zhang, J.; Ren, T. The Influence of Sorption Pressure on Gas Diffusion in Coal Particles: An Experimental Study. Processes 2019, 7, 219. [CrossRef]

18. Naveen, P.; Asif, M.; Ojha, K. Sorption Kinetics of $\mathrm{CH}_{4}$ and $\mathrm{CO}_{2}$ Diffusion in Coal: Theoretical and Experimental Study. Energy Fuels 2019, 31, 6825-6837. [CrossRef]

19. Liu, H.; Mou, J.; Cheng, Y. Impact of pore structure on gas adsorption and diffusion dynamics for long-flame coal. J. Nat. Gas Sci. Eng. 2015, 22, 203-213. [CrossRef]

20. Li, Z. Gas diffusion mechanism in multi-scale pores of coal particles and new diffusion model of dynamic diffusion coefficient. J. China Coal Soc. 2016, 41, 633-643.

21. Marquadt, D. An algorithm for least-square estimation of non-linear parameters. J. Appl. Math. 1963, 11, 431-441.

22. Wang, K.; Zang, J.; Feng, Y.; Wu, Y. Effects of moisture on diffusion kinetics in Chinese coals during methane desorption. J. Nat. Gas Sci. Eng. 2014, 21, 1005-1014. [CrossRef]

23. Wang, G.; Ren, T.; Qi, Q.; Lin, J.; Liu, Q.; Zhang, J. Determining the diffusion coefficient of gas diffusion in coal: Development of numerical solution. Fuel 2017, 196, 47-58. [CrossRef]

24. Guo, H.; Yuan, L.; Cheng, Y.; Wang, K.; Xu, C.; Zhou, A.; Zang, J.; Liu, J. Effect of moisture on the desorption and unsteady-state diffusion properties of gas in low-rank coal. J. Nat. Gas Sci. Eng. 2018, 57, 45-51. [CrossRef]

25. Staib, G.; Sakurovs, R.; Gray, E.M.A. A pressure and concentration dependence of $\mathrm{CO}_{2}$ diffusion in two Australian bituminous coals. Int. J. Coal Geol. 2013, 116, 106-116. [CrossRef]

26. Zang, J.; Wang, K.; Liu, A. Phenomenological Over-Parameterization of the Triple-Fitting-Parameter Diffusion Models in Evaluation of Gas Diffusion in Coal. Processes 2019, 7, 241. [CrossRef]

27. Zhao, W.; Cheng, Y.; Pan, Z.; Wang, K.; Liu, S. Gas diffusion in coal particles: A review of mathematical models and their applications. Fuel 2019, 252, 77-100. [CrossRef]

28. Zhang, Y. Geochemical Kinetics; Princeton University Press: Princeton, NJ, USA, 2008.

29. Mitra, P.P.; Sen, P.N.; Schwartz, L.M. Short-time behavior of the diffusion coefficient as a geometrical probe of porous media. Phys. Rev. B 1993, 47, 8565-8574. [CrossRef] [PubMed]

30. Kärger, J.; Ruthven, D.M.; Theodorou, D.N. Diffusion in Nanoporous Materials; John Wiley \& Sons: Hoboken, NJ, USA, 2012.

31. Loskutov, V.; Sevriugin, V.; Loskutov, V. A novel approach to interpretation of the time-dependent self-diffusion coefficient as a probe of porous media geometry. J. Magn. Reson. 2013, 230, 1-9. [CrossRef]

32. Liu, Y.; Teng, Y.; Lu, G.; Jiang, L.; Zhao, J.; Zhang, Y.; Song, Y. Experimental study on $\mathrm{CO}_{2}$ diffusion in bulkn-decane and n-decane saturated porous media using micro-CT. Fluid Phase Equil. 2016, 417, $212-219$. [CrossRef]

33. Valiullin, R.; Skirda, V. Time dependent self-diffusion coefficient of molecules in porous media. J. Chem. Phys. 2001, 114, 452. [CrossRef]

34. Faruk, C. Mass, Momentum, and Energy Transport in Porous Media. In Porous Media Transport Phenomena; Wiley Online Library: Hoboken, NJ, USA, 2011; pp. 281-351.

35. Jia, B.; Tsau, J.S.; Reza, B. Evaluation of Core Heterogeneity Effect on Pulse-decay Experiment. In Proceedings of the 31st International Symposium of the Society of Core Analysts, Vienna, Austria, 28 August1 September 2017.

36. Guo, H.; Cheng, Y.; Yuan, L.; Wang, L.; Zhou, H. Unsteady-State Diffusion of Gas in Coals and Its Relationship with Coal Pore Structure. Energy Fuels 2016, 30, 7014-7024. [CrossRef]

37. Nandi, S.P.; Walker, P.L. Activated diffusion of methane from coals at elevated pressures. Fuel 1975, 54, 81-86. [CrossRef]

38. Nie, B.S.; Yang, T.; Li, X. Research on Diffusion of Methane in Coal Particles. J. China Univ. Min. Technol. 2013, 42, 975-980. 
39. Yang, Q.L. Experimental Study on Gas Discharge Law of Coal Particles. Saf. Coal Mines 1987, 2, 9-16.

40. Yue, G.; Wang, Z.; Xie, C.; Tang, X.; Yuan, J. Time-Dependent Methane Diffusion Behavior in Coal: Measurement and Modeling. Transp. Porous Media 2017, 116, 319-333. [CrossRef]

41. Yang, Y.; Liu, S. Estimation and modeling of pressure-dependent gas diffusion coefficient for coal: A fractal theory-based approach. Fuel 2019, 253, 588-606. [CrossRef]

42. Wang, Y.; Liu, S. Estimation of pressure-dependent diffusive permeability of coal using methane diffusion coefficient: Laboratory measurements and modeling. Energy Fuels 2016, 30, 8968-8976. [CrossRef]

43. Jia, B.; Tsau, J.-S.; Barati, R. Different Flow Behaviors of Low-Pressure and High-Pressure Carbon Dioxide in Shales. SPE J. 2018, 23, 1452-1468. [CrossRef]

44. Saghafi, A.; Faiz, M.; Roberts, D. $\mathrm{CO}_{2}$ storage and gas diffusivity properties of coals from Sydney Basin, Australia. Int. J. Coal Geol. 2007, 70, 240-254. [CrossRef]

45. Ciembroniewicz, A.; Marecka, A. Kinetics of $\mathrm{CO}_{2}$ sorption for two Polish hard coals. Fuel 1993, 72, 405-408. [CrossRef]

46. Smith, D.M.; Williams, F.L. Diffusional Effects in the Recovery of Methane from Coalbeds. Soc. Pet. Eng. J. 1984, 24, 529-535. [CrossRef]

47. Busch, A.; Gensterblum, Y.; Krooss, B.M.; Littke, R. Methane and carbon dioxide adsorption-diffusion experiments on coal: Upscaling and modeling. Int. J. Coal Geol. 2004, 60, 151-168. [CrossRef]

48. Shi, J.; Durucan, S. A bidisperse pore diffusion model for methane displacement desorption in coal by $\mathrm{CO}_{2}$ injection. Fuel 2003, 82, 1219-1229. [CrossRef]

(C) 2019 by the authors. Licensee MDPI, Basel, Switzerland. This article is an open access article distributed under the terms and conditions of the Creative Commons Attribution (CC BY) license (http://creativecommons.org/licenses/by/4.0/). 